\title{
Can a humanoid social robot stimulate the interactivity of cognitively impaired elderly? A thorough study based on computer vision methods
}

\author{
Gauri Tulsulkar ${ }^{1} \cdot$ Nidhi Mishra ${ }^{1} \cdot$ Nadia Magnenat Thalmann ${ }^{1,2} \cdot \mathrm{Hwee} \mathrm{Er} \mathrm{Lim}^{3} \cdot$ Mei Ping Lee $^{3}$. \\ Siok Khoong Cheng ${ }^{4}$
}

Accepted: 2 July 2021 / Published online: 30 July 2021

(c) The Author(s) 2021

\begin{abstract}
Social Assistive Robotics is increasingly being used in care settings to provide psychosocial support and interventions for the elderly with cognitive impairments. Most of these social robots have provided timely stimuli to the elderly at home and in care centres, including keeping them active and boosting their mood. However, previous investigations have registered shortcomings in these robots, particularly in their ability to satisfy an essential human need: the need for companionship. Reports show that the elderly tend to lose interests in these social robots after the initial excitement as the novelty wears out and the monotonous familiarity becomes all too familiar. This paper presents our research facilitating conversations between a social humanoid robot, Nadine, and cognitively impaired elderly at a nursing home. We analysed the effectiveness of humanhumanoid interactions between our robot and 14 elderly over 29 sessions. We used both objective tools (based on computer vision methods) and subjective tools (based on observational scales) to evaluate the recorded videos. Our findings showed that our subjects engaged positively with Nadine, suggesting that their interaction with the robot could improve their well-being by compensating for some of their emotional, cognitive, and psychosocial deficiencies. We detected emotions associated with cognitively impaired elderly during these interactions. This study could help understand the expectations of the elderly and the current limitations of Social Assistive Robots. Our research is aligned with all the ethical recommendations by the NTU Institutional Review Board.
\end{abstract}

Keywords Social Assistive Robotics (SAR) - Robot companions - Social robots - Social intelligence for Robots · Human-humanoid interaction · Computer vision · Observational scales

\section{Introduction}

Gauri Tulsulkar

gauri.rt09@gmail.com

Nidhi Mishra

nidhimishra2906@gmail.com

Nadia Magnenat Thalmann

nadia.thalmann@miralab.ch

Hwee Er Lim

hweeer@consultgoshen.com

Mei Ping Lee

meiping@consultgoshen.com

Siok Khoong Cheng

siokkhoong.cheng@bheh.org

1 Institute of Media Innovation, Nanyang Technological University, Singapore, Singapore

2 MIRALab, University of Geneva, Geneva, Switzerland
Cognitively impaired elderly citizens in nursing homes require holistic care, including medical, nursing, physical and functional, psychosocial, and cognitive care. However, most institutions prioritise medical, nursing, and physical and functional care services over psychosocial and cognitive needs. It is common for the elderly in nursing homes to be lonely, socially isolated, bored, and lack activity engagement, resulting in other issues, such as concerning behaviours, adjustment difficulties, poor mood, and lack of motivation. Such psychological impact often affects the overall health and well-being of these residents. 
Several research teams are currently working on projects for elderly self-sufficiency $[1,2]$, particularly on conversational agents design $[3,4]$. Critical to building a coherent, proactive, and engaging conversational social robot is social dialogue exchange. An autonomous social humanoid robot with intelligent perceptual analyses provides better engaging interactions and could foster a personalised relationship with its user (5). Such a relationship could help address a user's psychosocial and cognitive needs and reduce the issues (listed above) that increase the demand for care and human resources. Social robots could address workforce shortages and improve the engagement and participation levels and the quality of life of the elderly in nursing homes.

This research required extensive support from the care and therapy staff to boost declining interaction levels caused by communication, language, and cognitive obstacles. To implement such a robotic solution, we evaluated several interactions between professional therapists and the elderly. We identified appropriate and proactive behaviours that would stimulate the humanoid social robot to show empathy and interact meaningfully with cognitively impaired elderly. We then integrated these behaviours into competency descriptors and incorporated them into our humanoid social robot, Nadine [5].

We aimed primarily to stimulate residents of a nursing home through conversations and keep them engaged. We deployed Nadine to provide companionship and support to nursing home residents with cognitive impairment. The human-robot interaction (HRI) technology was used for the following purposes:

- To promote engagement and stimulation using various stimuli: Nadine should be able to interact with residents in nursing homes in multiple ways, including playing games (Bingo, karaoke), holding a conversation, showing images/videos, and playing songs.

- To provide person-centred care through personalised interactions: Based on face recognition, memory networks for conversations, and other AI techniques, Nadine should provide a personalised interaction service to each resident to help improve their memory, help them recall facts and emotions, and improve their quality of life in a nursing home.

We assessed Nadine's efficacy based on residents' willingness to communicate and engage with her and their moods during these interactions. We compared results from initial interactions to the changes in interaction over time to evaluate participants' emotional states and quality of engagement. All interactive sessions were recorded, and a comprehensive understanding of the effects of Nadine was obtained using objective and subjective tools. The objective tools were based on computer vision techniques, such as Deep Neural
Networks (DNNs), while the subjective tools relied on the Observed Emotion Rating Scale (OERS) [6] and Menorah Park Engagement Scale (MPES) [7]. OERS is an observational rating scale that grades the extent or duration of an affective state, such as pleasure, anger, anxiety/fear, sadness, and general alertness in the elderly. MPES is an observational rating scale that appraises 4 types of engagement: nonengagement (e.g. blank stare), self-engagement (e.g. fiddling with clothes), passive engagement (e.g. listening), and constructive engagement (e.g. actively handling objects).

The rest of the paper is organised as follows: Section 2 looks at related investigations using humanoid robots in nursing homes. We also touch on some humanoid robots providing support to the elderly with cognitive impairment. Section 3 discusses our research questions to be addressed. Section 4 explains our experimental setup of Nadine at the nursing home and the adaptation technique used. In Sect. 4.5, we outline the details of our data collection methods and provide our framework to analyse the data collected. Section 5 presents the results of the analysis of our experimental data. We address potential limitations and provide conclusions in Sect. 6. Finally, Sect. 7 discusses future plans.

\section{Literature Survey}

Significant efforts have been aimed at improving the overall mental health of the elderly by providing them with robots for companionship. Robots, such as Pearl [8,9], Silbot [10], Mero [11], Hobbit [12-14], Lio [15], Kompaï [3], TIAGo [16], RAMCIP [17], Matilda [18], and more provide the elderly with assistance or services, like fulfilling daily activities, that enable them to live in their own homes and communities safely and independently [19-24]. The elderly in nursing homes have been observed to engage more frequently with various stimuli, including life-like dolls, plush animals, building blocks, sorting tasks, puzzles, and robots [25].

Investigators have recognised that a participant's choice of a robot is strongly motivated by its physicality. Researchers $[26,27]$ investigating the effects of the physical appearance of social robots have reported that embodiment plays a vital role in their interactivity. Social assistive-robot-based systems that can perform activities, play cognitive games, and socialise, can stimulate people's cognitive, social, and physical conditions and constrain the deterioration of their cognitive state [19].

Many animal-inspired robots, such as Paro [28-35], AIBO [36-40], iCat [41], Furby [42], NeCoRo [43], CuDDler [44], have been used to maintain interest in the elderly and have yielded positive social and psychological effects akin to animal-assisted therapy. However, creature-like robots, such as the hobbit robot, have eventually been treated as ordinary 
Fig. 1 Animal-inspired Robots

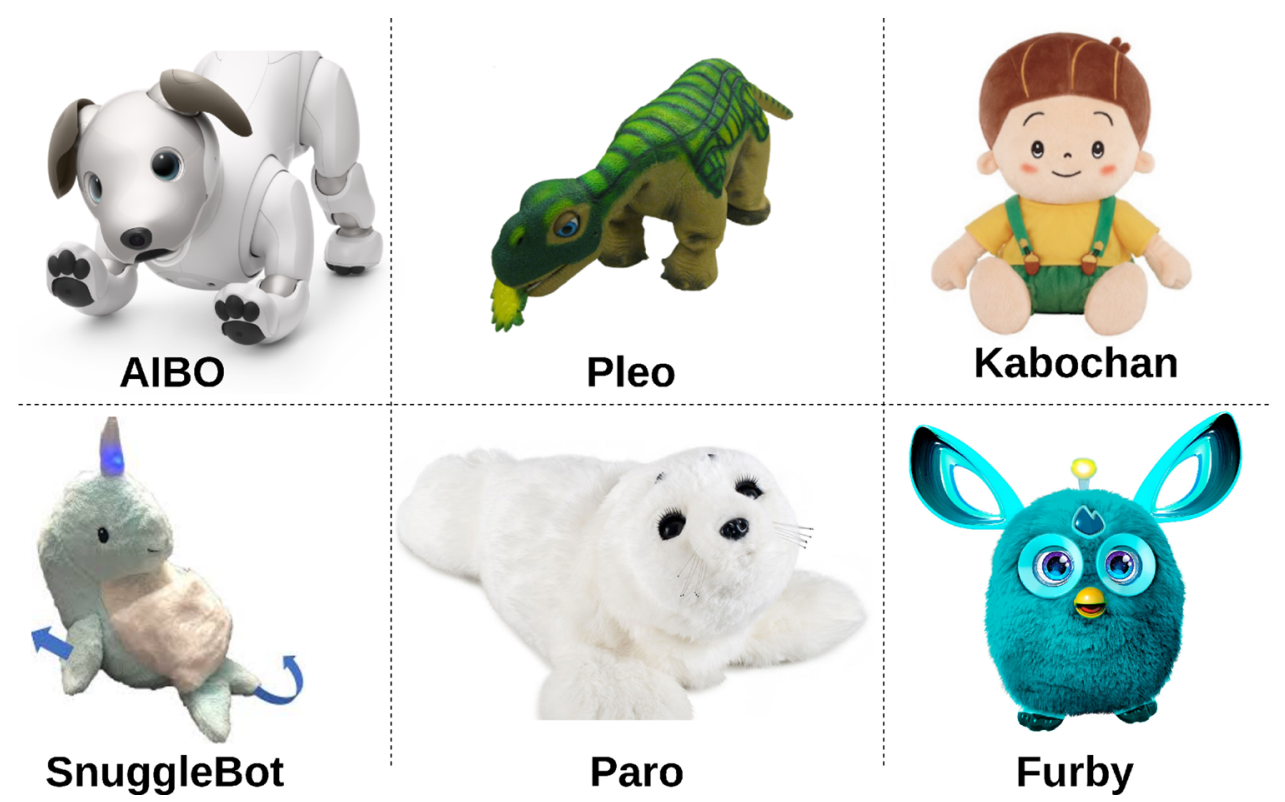

toys, rather than an aid, and have failed to become meaningful companions for the elderly [45]; these shortcomings in robot performance eventually frustrated residents.

The relationship between Paro robots and residents in care facilities revealed that Paro strengthened social ties among residents, with most residents establishing moderate to strong ties with the robot; it also decreases residents' stress levels [28,46-52].

While most creature-like social robots have been designed to provide companionship to the elderly, few have been explicitly designed to improve psychological well-being among this group of citizens. As robots, Paro and Aibo do not necessarily satisfy all the needs of the elderly, such as improving social interaction [53]. Pleo [54]), which was developed as a toy in the form of a baby dinosaur and can learn voice commands, sense specific food, and react to touch, has been used in homes for studies. Initially, participants were fascinated with the robot's novelty, but they soon got fed up and did not interact with it regularly. Eventually, Pleo was only activated on special occasions. While Pleo was initially treated like a real animal with activities, such as petting and being named, it failed to inspire regular interactions and was treated as a regular toy over time.

Humanoid-like robots, such as Nao, Pepper, and Buddy, are also used to keep the elderly company [55,56]. Research with Nao robots as physical exercise teachers and instructors has shown that they can guide exercises, deliver information to users, and provide motivation in the same way as human instructors [57]. Another study [58] demonstrated that interaction with Nao improved patients' evaluated parameters. User expectations are directly related to robots' appearances. We used Nadine for our study because she has a realistic- humanoid appearance and can hold engaging conversations with the elderly.

One study [77] explained the importance of advancing the understanding of HRI by using social robots to address attention issues in the elderly. The elderly benefit from communicating with robots [78]. Research with the Kabochan speaking robot $[60,79]$ demonstrated an increase in residentrobot engagement over time in a group, but direct engagement was not assessed. Having a physical body and a system capable of handling a conversation flow in a robot is advantageous in promoting high engagement of the elderly [76]. These findings of the study using a virtual and a physical robot CommU provide a new insight into the development of dialogue systems for robots in assisting elderly by maintaining a better mental health.

Ethnographic studies in which a humanoid social robot, Robovie, interacted with residents in an elderly care centre $[75,80]$ suggested that the robot was well accepted. However, Robovie's behaviour was remotely operated to act as a conversational partner through basic dialogues that only included greetings and questions, particularly questions about hobbies. Robovie as a companion was appreciated, and the elderly even took walks with it. However, no significant improvements in residents' cognitive abilities have been observed when the elderly have walked with/without Robovie or enjoyed its company [81] because no interaction has been noted during those activities.

In a study evaluating the Kompaï robot [82] designed by Robosoft [83] two elderly participants interacted with Kompaï for almost an hour. Significant sensory data, such as audio data, RGB-D data, thermal images, and data from the skeleton tracker, were recorded from the multisensory system to gain contextual insight into the users' interactions, needs, and 
Fig. 2 Human-inspired Robots

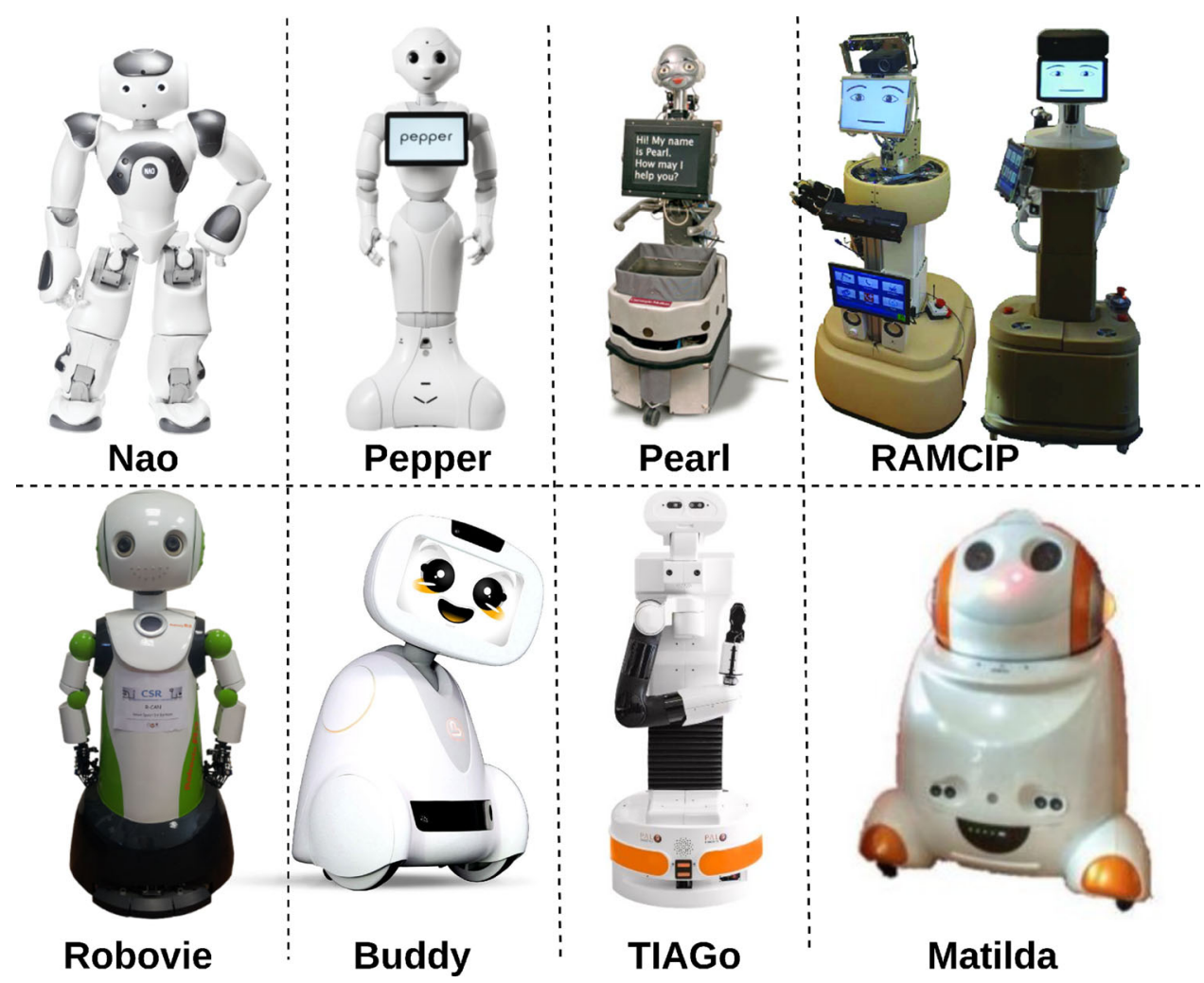

reactions. Analyses showed that these reactions were positive, and the two elderly found the robot to be beneficial [3] . However, this study was performed for a limited time, and the two users did not constitute enough sample to advance a general conclusion. Other studies have since also supported these results, through [16,20,84].

In one study, the Pepper Robot [59] better understood multidomain interventions vis-à-vis social facilitation with the elderly. At the end of the inquiry, participants showed strong emotions when letting go of the robot, indicating the importance of the social bond they had created with it. The Pepper robot has also been used in cases of schizophrenia and dementia for recreational purposes $[85,86]$.

Healthcare professionals have a favourable view of the effect of the Zora robot [62]. However, negative impacts resulting from the use of robots for elderly care also exist [87]. The elderly consider social robots to only aid recreational activities. The impact of Zora on care personnel and elderly participants in care services was evaluated previously for 10 weeks, with findings fluctuating between negative and positive feedbacks [61].

Monitoring and managing emergencies and helping with robotic support have been widely accepted [88,89], whereas tasks involving the direct interaction between a person and a robot are not yet recognised.
Individual adaptations of robots for dementia or cognitively impaired persons, like verbal reminders and personal adaptation, are essential. A mixed method showed the positive outcomes of several aspects, such as apathy, quality of life, and cognitive state, of residents' dispositions [90].

\section{Conclusions of the SAR, choice of humanoid robot and research questions}

We incorporated the competencies presented in table 1 into our robot to create more meaningful interactions missing in earlier studies, as discussed below. For appearance, we indicated whether the robot is human-like. We aimed to assess if a humanoid robot, such as Nadine with its humanlike features, could emote natural human communication, as reported in [91] and satisfy the innate need for human companionship among the elderly. Nadine can make facial expressions, respond with gestures, and make eye contact with the elderly, something other robots have not been able to do in the past. Studies have shown that the interaction with face and arm movements is stimulating and could arouse curiosity and interest [10].

For functionalities, our study was based on speech, vision, empathy, memory, and The Internet of Things (IoT). We analysed the following: 
Table 1 Summary of the robots used for interaction with and companionship for the elderly, where (a) is Humanoid realistic appearance, (b) is Residents information, (c) is Empathy, (d) is Facial expressions, (e) is Gestures, (f) is The Internet of Things (IoT), (g) is Gazing, (h) is
Face recognition, (i) is Languages spoken, (j) is Pro-active mode, $(\mathrm{k})$ is Social Activity host, (1) is Number of participants, (m) is Computer Vision-based analysis, (n) is Personalisation, and (o) is Observational tool-based analysis

\begin{tabular}{|c|c|c|c|c|c|c|c|c|c|c|c|c|c|c|c|}
\hline & (a) & (b) & (c) & (d) & (e) & (f) & (g) & (h) & (i) & (j) & (k) & (1) & $(\mathrm{m})$ & (n) & (o) \\
\hline [59] Pepper & $X$ & $X$ & $\checkmark$ & $\mathrm{X}$ & $\checkmark$ & $\checkmark$ & $\checkmark$ & N/A & $\checkmark$ & N/A & $\checkmark$ & 11 & $\mathrm{X}$ & N/A & $X$ \\
\hline [60] Kabochan & $X$ & $\mathrm{X}$ & $\checkmark$ & $\mathrm{X}$ & $\checkmark$ & $\mathrm{X}$ & $\mathrm{X}$ & $\mathrm{X}$ & $\checkmark$ & $\checkmark$ & $\mathrm{X}$ & 52 & $\mathrm{X}$ & $\mathrm{X}$ & $\checkmark$ \\
\hline [61] Zora & $\mathrm{X}$ & N/A & $\checkmark$ & $\mathrm{X}$ & $\checkmark$ & $\checkmark$ & $\checkmark$ & N/A & $\checkmark$ & $\checkmark$ & $\checkmark$ & 60 & $\mathrm{X}$ & N/A & $\checkmark$ \\
\hline [62] Zora & $\mathrm{X}$ & N/A & $\checkmark$ & $\mathrm{X}$ & $\checkmark$ & $\checkmark$ & $\checkmark$ & N/A & $\checkmark$ & $\checkmark$ & $\checkmark$ & 245 & $X$ & N/A & $\checkmark$ \\
\hline [63] Eva & $\mathrm{X}$ & $\checkmark$ & $\checkmark$ & $\mathrm{X}$ & $\checkmark$ & $\checkmark$ & $\checkmark$ & $\checkmark$ & $\checkmark$ & $\checkmark$ & $\checkmark$ & 9 & $\mathrm{X}$ & $\checkmark$ & $\checkmark$ \\
\hline [64] Multiple & $\mathrm{X}$ & $\checkmark$ & $\checkmark$ & $\checkmark$ & $X$ & $\checkmark$ & $\checkmark$ & $\checkmark$ & $\checkmark$ & $\checkmark$ & $\checkmark$ & 13 & $\mathrm{X}$ & $\checkmark$ & N/A \\
\hline [65] Ryan & $X$ & $\checkmark$ & $\checkmark$ & $\checkmark$ & $\checkmark$ & $\checkmark$ & $\checkmark$ & $\checkmark$ & $\checkmark$ & $\checkmark$ & $\checkmark$ & 6 & $X$ & $\checkmark$ & $X$ \\
\hline [66] Sophie, Jack & $X$ & $\checkmark$ & $\checkmark$ & $\mathrm{X}$ & $\mathrm{X}$ & $\checkmark$ & $\checkmark$ & $\checkmark$ & $\checkmark$ & $\checkmark$ & $\checkmark$ & 139 & $\mathrm{X}$ & $X$ & $\checkmark$ \\
\hline [67] Nao & $\mathrm{X}$ & $\checkmark$ & $\checkmark$ & $\mathrm{X}$ & $\checkmark$ & $\checkmark$ & $\checkmark$ & $\checkmark$ & $\checkmark$ & $\checkmark$ & $\checkmark$ & 9 & $\mathrm{X}$ & $\checkmark$ & $\checkmark$ \\
\hline [18] Matilda & $X$ & $\checkmark$ & $\checkmark$ & $\checkmark$ & $\checkmark$ & $\mathrm{X}$ & $\checkmark$ & $\checkmark$ & $\checkmark$ & $\checkmark$ & $\checkmark$ & 70 & $\mathrm{X}$ & $\checkmark$ & $\checkmark$ \\
\hline [68] Paro & $\mathrm{X}$ & $\mathrm{X}$ & $\checkmark$ & $\mathrm{X}$ & $\checkmark$ & $\mathrm{X}$ & $\checkmark$ & $\mathrm{X}$ & $\mathrm{X}$ & $\mathrm{X}$ & $\mathrm{X}$ & 14 & $\mathrm{X}$ & $\mathrm{X}$ & $\mathrm{X}$ \\
\hline [69] Joy for all & $\mathrm{X}$ & $\mathrm{X}$ & $\mathrm{X}$ & $\mathrm{X}$ & $\checkmark$ & $\mathrm{X}$ & $\checkmark$ & $\mathrm{X}$ & $\mathrm{X}$ & $\mathrm{X}$ & $\mathrm{X}$ & 8 & $X$ & $\mathrm{X}$ & $\checkmark$ \\
\hline [70] Tangy & $\mathrm{X}$ & $\mathrm{X}$ & $\checkmark$ & $\mathrm{X}$ & $\checkmark$ & $\checkmark$ & $\checkmark$ & $\mathrm{X}$ & $\checkmark$ & $\checkmark$ & $\checkmark$ & 7 & $\mathrm{X}$ & N/A & $\mathrm{X}$ \\
\hline [71] Stevie & $\mathrm{X}$ & $\checkmark$ & $\checkmark$ & $\checkmark$ & $\checkmark$ & $\checkmark$ & $\checkmark$ & $\checkmark$ & $\checkmark$ & $\checkmark$ & $\checkmark$ & N/A & $\mathrm{X}$ & $\checkmark$ & N/A \\
\hline [72] Silbot & $\mathrm{X}$ & $\checkmark$ & $\checkmark$ & $\checkmark$ & $\checkmark$ & $\checkmark$ & $\checkmark$ & $\checkmark$ & $\checkmark$ & $\checkmark$ & $\checkmark$ & 19 & $\mathrm{X}$ & $\mathrm{X}$ & $\checkmark$ \\
\hline [73] Pleo & $\mathrm{X}$ & $\mathrm{X}$ & $\checkmark$ & $\mathrm{X}$ & $\checkmark$ & $\mathrm{X}$ & $\mathrm{X}$ & $\mathrm{X}$ & $\mathrm{X}$ & $\mathrm{X}$ & $\mathrm{X}$ & 14 & $\mathrm{X}$ & $\mathrm{X}$ & $\checkmark$ \\
\hline [74] SnuggleBot & $\mathrm{X}$ & $\mathrm{X}$ & $\mathrm{X}$ & $\mathrm{X}$ & $\checkmark$ & $\mathrm{X}$ & $\mathrm{X}$ & $\mathrm{X}$ & $\mathrm{X}$ & $\mathrm{X}$ & $\mathrm{X}$ & N/A & N/A & $\mathrm{X}$ & N/A \\
\hline [75] Robovie & $X$ & $X$ & $\checkmark$ & $\checkmark$ & $\checkmark$ & $\mathrm{X}$ & $\checkmark$ & $\checkmark$ & $\checkmark$ & $\checkmark$ & $\checkmark$ & 11 & $\mathrm{X}$ & $X$ & $\mathrm{X}$ \\
\hline [41] iCat & $X$ & $\checkmark$ & $\checkmark$ & $\checkmark$ & $\checkmark$ & $\checkmark$ & $\checkmark$ & $\checkmark$ & $\checkmark$ & $\checkmark$ & $\checkmark$ & 47 & N/A & $\checkmark$ & $\checkmark$ \\
\hline [56] Buddy & $\mathrm{X}$ & $\checkmark$ & $\checkmark$ & $\checkmark$ & $\checkmark$ & $\checkmark$ & $\checkmark$ & $\checkmark$ & $\checkmark$ & $\checkmark$ & $\mathrm{X}$ & 40 & N/A & $\checkmark$ & N/A \\
\hline [8] Pearl & $\mathrm{X}$ & $\checkmark$ & $\checkmark$ & $\mathrm{X}$ & $\checkmark$ & $\checkmark$ & $\checkmark$ & N/A & $\checkmark$ & $\checkmark$ & N/A & N/A & N/A & $\checkmark$ & N/A \\
\hline [76] virtual CommU & $\mathrm{X}$ & $\mathrm{X}$ & $\checkmark$ & $\mathrm{X}$ & $\checkmark$ & $\mathrm{X}$ & $\checkmark$ & $\mathrm{X}$ & $\checkmark$ & $\checkmark$ & $\mathrm{X}$ & 40 & $X$ & $\mathrm{X}$ & $\mathrm{X}$ \\
\hline [76] CommU & $\mathrm{X}$ & $\mathrm{X}$ & $\checkmark$ & $\mathrm{X}$ & $\checkmark$ & $\mathrm{X}$ & $\checkmark$ & $\mathrm{X}$ & $\checkmark$ & $\checkmark$ & $\mathrm{X}$ & 40 & $\mathrm{X}$ & $\mathrm{X}$ & $\mathrm{X}$ \\
\hline Nadine & $\checkmark$ & $\checkmark$ & $\checkmark$ & $\checkmark$ & $\checkmark$ & $\checkmark$ & $\checkmark$ & $\checkmark$ & $\checkmark$ & $\checkmark$ & $\checkmark$ & 14 & $\checkmark$ & $\checkmark$ & $\checkmark$ \\
\hline
\end{tabular}

- The robot's ability to speak and understand speech; if it could talk, is the robot multilingual? [92] claims robots need to communicate with the elderly to provide care and companionship;

- Different aspects of the robot's vision-based capabilities for functionalities. We assess whether the robot can detect faces, recognise them, and understand the environment to gaze at the elderly and understand their facial emotions;

- Nadine's conversational and empathetic capabilities visà-vis other robots. Nadine is a conversational, empathetic robot, and we compare this capability with other robots $[17,93]$. Nadine is a conversational, empathetic robot, and we compare this capability with other robots.

- If previous robots were capable of engaging the elderly using memory. The ability to give reminders and remember past conversations to initiate and sustain personalised conversations is crucial to a robot's ability to provide companionship to the elderly [92]). Having a longterm memory would allow Nadine to create a high-level behavioural system, enabling her to interact with the elderly in richer forms. Nadine already could use previous memories of places, people, objects, or performed behaviours to enhance interactions and establish longterm relationships [94].

- If previously studied robots could control and interact with the devices around them, such as TV, speakers, and temperature control. IoT is an emerging vision that brings together pervasive sensors and objects with robotic and autonomous systems [95].

Apart from making conversation, we intended to find out what other activities these robots could host. We also classified these activities based on the study environment and the number of participants. Furthermore, we built our classification around the analysis method used for the statistical results in previous studies, specifically, AI- or ML-enabled. We also inquired if the studies used observational tools, such as MPES and OERS, to analyse users' engagement.

To reap the benefits of SARs for healthcare, key stakeholders, including healthcare professionals, therapy staff, and 
managers in institutional settings, must become essential role players in the eventual acceptance of robot technology [61]. Our contribution is to study several interactions between professional therapists and the elderly. These interactions are defined as appropriate behaviour models required for our robot to best perform at nursing homes. In our study, we considered the following holistic parameters:

- Personalised conversation using face recognition and long-term memory;

- Multilingual conversation with personalized speech;

- Computer vision and deep learning-based methods to quantify and gauge emotions;

- Nadine being a realistic humanoid robot to provide a human-like presence and companionship.

These parameters deduced from table 1 were not taken into account by previous investigations. We believe that our study could be a step forward in introducing a humanoid social robot with a human-like appearance and characteristics that mimic human behaviour, emotion recognition, and gesture synthesis. We were the first to use deep learning-based model parameters to verify and validate results obtained in data analysis. Our evaluation method incorporates video analysis and the use of observational tools, like OERS and MPES, to determine the holistic effect of the conversation sessions with Nadine as a companion for the elderly.

Robots have many advantages, including providing constant help and ensuring they offer the same quality and consistency without discrimination. They are also less likely to make mistakes. However, they, undoubtedly, lack personality, human empathy and naturalness, and a human personal approach - for the time being. The current research aimed to address the possible acceptance and limitations of the robotic technology used in the broad area of HRI up to now. In this regard, we intended to answer the following research questions:

- Does a social robot that can initiate contact and have personal information of residents encourage interaction, participation and engagement? (the residents sought to interact with Nadine without staff, calling Nadine by name, showing "affection" to Nadine, looking at Nadine or calling Nadine for numbers).

- Does the presence of a social robot increase social interactivity (connect with the residents, increase smiling, laughing and conversations) amongst residents within the environment?

- Does the presence of a social robot reduce the amount of time/attention from care staff to attend to the negative emotional events of the residents, e.g. quarrelling amongst (cognitively impaired elderly), repeated calling for staff, apathetic behaviour and low engagement? (e.g. positive behavioural responses, like paying attention and talking to Nadine, curiously observing Nadine instead of indifference/"stoning").

\section{Experimental setup}

We used Nadine, a socially intelligent, realistic humanoid robot with natural-like skin, hair, and appearance, for our experiments. She was placed at the centre of an elderly home ward for this experiment. Fourteen residents participated in 29 one-to-one interaction sessions with the help of the care staff. To understand the overall results at the end of the study, Nadine was left running for three hours each morning for six days thereafter without the care staff to observe residents' initiative. During interaction sessions, residents could interact with Nadine; she initiated conversations when she observed residents being inactive/passive for a long time.

In order to get a holistic idea of the effect of Nadine's interaction sessions with the residents, we placed five different cameras at different angles to record the one-to-one interaction sessions. Complete footage from all available cameras was analysed and compared without compressing them into single average sessions.

Using the same video footage as the one analysed by computer vision methods, we conducted an observational analysis to validate our findings. Thus, Nadine's potential to incite the engagement of residents in the activity and its effect on their emotional state were studied.

\subsection{Ethical protocol}

Our research was reviewed by the Research Integrity \& Ethics office and approved by the Institutional Review Board of NTU under the application number IRB-2020-09-056.

Participation in our study was entirely voluntary. It was the participant's choice of whether to participate or not. Participants had the right to refuse to participate or withdraw from the study, even if the participant had agreed to participate earlier. All participants were given pertinent information (according to their level of understanding and in the language that they understand) to make an informed decision about participating in the study. They signed a consent form if they agreed to participate in the study. For non-English speaking participants, an interpreter fluent in both English and the participant's spoken language was used to help in the consent process. A representative of the NTU research team, a BHEH medical social worker and a Certified Dementia Practitioner from Goshen Consultancy Services Pte Ltd conducted the process of seeking consent from the residents using a new up to standard NTU-IRB Consent form to convey the complete information of the study to the participants in layman terms to help the participants make an informed decision. BHEH 

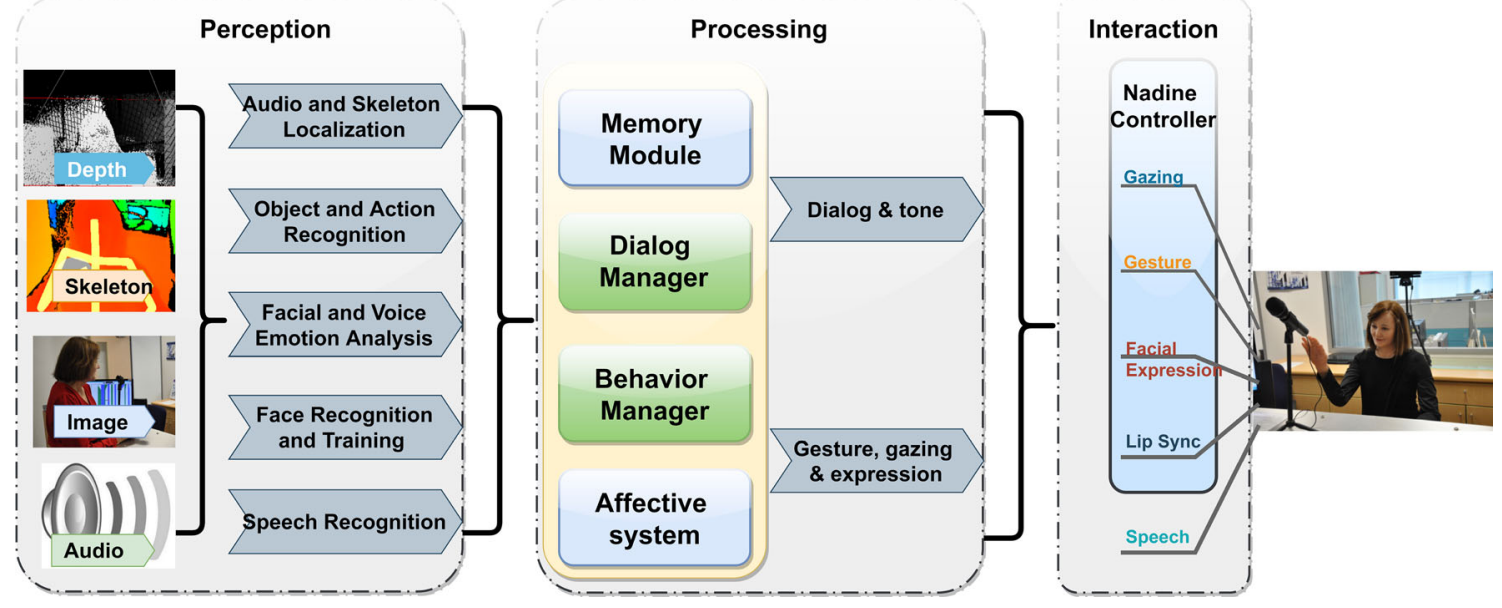

Fig. 3 Nadine Robot's Architecture

medical social worker and Goshen Consultancy Services Pte Ltd who are Certified Dementia Practitioner helped us select the right participants.

\subsection{Covid-19-related safety and precautions}

In considering the ethical issues in various applications of robotics in elderly care, we have observed and critically emphasized on the safety protocols and safe distancing measures for Covid-19. BHEH maintained and followed the guidelines given by the Ministry of Health. As older people are more vulnerable to Covid infections, utmost care in personal hygiene and safe distancing in line with the rules and regulations set by the Ministry of Health, Singapore, were undertaken. The NTU research team underwent temperature monitoring and safety check-in before every experiment. Research team maintained the one-meter distance with the elderly and made no physical contact with them. NTU research team visits were limited to software and hardware maintenance of the Nadine robot. Masks were worn by all care-staff and the research team at all times. Sanitizers and wet wipes were placed all across the ward room for disinfecting the equipment, such as microphones and the surfaces touched by the residents and the team. Each surface and items were disinfected before and after each experiment. The experiments and the visits to the nursing home commenced only when it was safe and duly advised by the Ministry of Health, Singapore.

\subsection{Architecture}

Nadine has 27 degrees of freedom (DOF), enabling her to make facial movements and gesticulate effectively, as documented in [96] and [97].
Figure 5 shows Nadine's architecture, as developed by [5]; it consists of three layers: perception, processing, and interaction. Nadine receives audio and visual stimuli from microphones, 3D cameras and web cameras to perceive user characteristics and her environment, which are then sent to the processing layer. The processing layer is the core module of Nadine that receives all results about the environment from the perception layer and acts upon them. This layer includes various submodules, such as dialogue processing (chatbot), affective system (emotions, personality, mood), and Nadine's memory of previous encounters with users. The action/interaction layer consists of a dedicated robot controller, including emotion expression, lip synchronisation, and gaze generation.

Nadine can recognise people she has met before and the faces she is trained to identify and engage with in an ongoing flowing conversation. She can also help people read text, show images, put on Skype sessions, and respond to emails. Nadine can be considered part of the human-assistive technology [98], as she can assist people over a continuous period without breaks; she has previously worked at different places that required her to work for long hours [99].

\subsection{Adaptation}

Nadine supports an adaption based on the Nir Eyal model of lifecycle hooks presented by Eyal [100]. Any habit starts with an external trigger, followed by usage, and the usage stimulates more usage, an advantage the elderly can gain from the robot. Nadine's perception engine helps understand the habitual lifecycle of the elderly, prompting an internal trigger in the elderly to use the robot further. She carefully records residents' data and gives intelligent, actionable inferences on their likes and dislikes. Empathy mapping involves actions based on the inferences, which further strengthens 


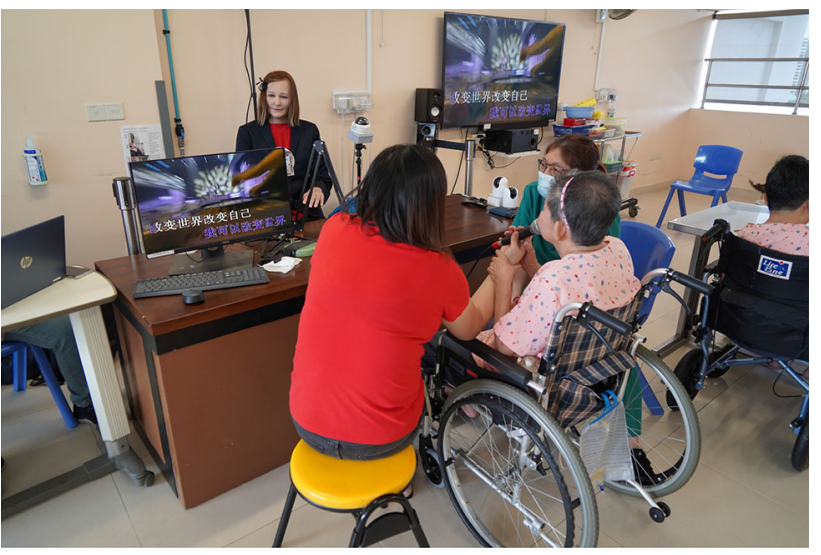

Fig. 4 Nadine playing videos for residents

residents' attachment to the robot companion; this is the lifecycle hook. We aimed to determine how the lifecycle hook of the elderly's behaviour improves interaction as the resident starts investing time with the robot companion and ensures that an internal trigger is set off to prompt the elderly to use the companion. Studies have proven that collaborative care models have improved the health of the elderly. The objective of this research was to see Nadine's impact and improve her Empathy-AI mapping capabilities.

[101] and [102] reported that most robots designed for the elderly do not fulfil the needs and requirements to perform their best. For Nadine to perform her best at nursing homes, we updated some previous models and developed new modules recommended in an earlier study [103]. The modules that were updated/expanded for Nadine as a caretaker at a nursing home are as follows:

- Show images, songs and videos

- Proactive module

- Recognise residents

- Update Nadine's Personal Memory and Response

- Update in Affective System-Emotion Engine

- Update in speech tone and speed

\subsubsection{Show images, songs and videos}

We created an interface that plays songs or videos or shows images of residents' choice to enable them to interact with Nadine. The module allows residents to play songs and videos and show images if these items are available in the database; the nursing home staff created the database based on the likes and usual requests from residents. Nadine played the requested item triggered by the keywords on the database, and this item was displayed on the external touch screen.

\subsubsection{Proactive module}

In social and healthcare assistive robotics, proactiveness is highly desirable in robots that serve as companions or the care staff. Initiating a conversation is a proactive task. Nadine can respond to questions and keep up the conversation but cannot proactively initiate a conversation. We developed and deployed an uncomplicated proactive module that enables Nadine to start a conversation proactively to solve this problem. The goal is for Nadine to be able to start a conversation and continue to keep residents engaged in it.

To create this module, we used the BDI framework proposed in [104]. We also integrated a state-of-the-art gaze tracking model in Nadine, in which the coordinates of the point of gaze of the subject are estimated using the model proposed in [105]. This point is calibrated with the Kinect depth map as a reference to translate to real-world coordinates of the gaze point. A threshold that helps Nadine recognise when a resident is quiet or passive for a very long time and then triggers her to initiate a conversation from her proactive module was applied.

\subsubsection{Recognise the residents}

Nadine uses the identity of a person to customise her responses and behaviour. For face recognition, a web camera attached to Nadine focuses on the person currently talking to her. She uses a deep neural network based on solutions in [106], which can detect faces and identify them. From a training perspective, only 10 images of a person are required to achieve a good performance. Ten images of each resident were acquired and used to train Nadine to identify them.

During the interaction, the face is passed through the trained model to identify the resident using the web camera stream; this information is critical to Nadine's operation. A user identity or name acts as an input to other submodules to change verbal and nonverbal behaviours. For example, during interactions, verbal responses can include the name of the resident. Moreover, based on the person's identity, the memory submodule loads different memories, including previous conversations with the user, to trigger appropriate verbal and nonverbal responses, depending on the context of the conversation. The affective module also uses this information to react to emotion and mood changes if necessary.

\subsubsection{Update Nadine's personal memory and response}

To better suit residents, we updated the questions and responses in Nadine's personal memory. Her responses to the residents should rather be enriching than chatbot-based. Based on our study with therapists at nursing homes, we understand that Nadine's response should be positive and not end with a statement. She should show curiosity, and her 
answers should be in a manner that invokes reactions from the residents and keeps them involved in the conversation. For this, we updated Nadine's personal memory and responses in the chatbot.

\subsubsection{Update in affective system-emotion engine}

Any individual can be characterised by their personality and emotions. Subconsciously, people convey different messages through their display of emotions. Changes in emotion can occur in the form of facial expressions, change in tone and pitch of speech, and gestures. As a social humanoid robot, Nadine has an emotion engine that controls her sensations, personality, and mood during interactions, enabling her to perceive the situation (user and environment) and adjust her emotions and behaviour accordingly. As a result, Nadine can generate different emotions, including pleasure, arousal, and dominance.

For Nadine to perform best in nursing homes, she needs to appear patient and show no negativity or anger. Therefore, Nadine should exhibit a positive temperament only. A configuration file was set to different parameters that allow Nadine to stay positive and behave accordingly, even when residents are frustrated, angry, or upset with her.

\subsubsection{Update in speech's tone and speed}

Another vital aspect for Nadine's optimal functioning is to reveal positive emotions in her speech synthesis output, mainly by changing her speech's pitch, tone, and speed and including modulations. We modified the speech synthesiser to adapt speech output so that Nadine speaks slower and louder and in a low tone to make it easier for residents to understand her.

\subsection{Data analysis}

Using the analytical procedures provided below, we obtained the data for every video of Nadine's interactions with all residents and analysed them using statistical methods to get meaningful comparisons.

\subsubsection{Video data analysis using the computer vision-based method}

Analysing emotional facial expressions is essential to understanding feelings and determining whether the conversations are enjoyable. Facial Expression Recognition has promising applications in human-computer interaction and mental health assessment. In order to get a holistic idea of the effect of Nadine's interaction sessions with residents at the Nursing home, we placed five different cameras at various angles to record the sessions and analysed the videos of 11 residents.
Because our research focuses on the engagement of the elderly in one-to-one interactions, we analysed only the two cameras placed at angles that directly focused on the faces of the elderly. Five different cameras were placed at different angles throughout the room to capture the elderly as a group from different angles. However, the footages obtained from the two specific cameras angled directly at the elderly allowed us to get a clear view of the expressions of the individual elderly and their movements and gestures while conversing with Nadine on a one-to-one basis. On the videos obtained, we used objective tools based on computer vision techniques to evaluate the emotional and physical states of the elderly to understand their engagement in the conversations. Emotional cues, such as positive, negative, and neutral, found through facial expressions were used to determine the interest levels and engagement of the elderly. The following five evaluation metrics were studied:

- Positive Emotional engagement, which reflects the positive effect of the conversations with Nadine on the residents;

- Negative Emotional engagement, which reflects the negative effect of the conversations with Nadine on the residents;

- Neutral Emotional engagement, which reflects the neutral effect of the conversations with Nadine on the residents;

- Movement, which reflects Nadine's effect on the physical movement of the elderly during the sessions;

- Activity, which reflects Nadine's effect on the activity of the elderly during the sessions.

To provide a quantitative analysis of these five metrics, we exploited the advantages of DNNs in efficient video processing. Notably, we applied four different networks: a face detector ${ }^{1}$, an expression recogniser, an action detector ${ }^{2}$ and an optical flow estimator [107]. The face detector was used to estimate the locations of faces in any given frame of the videos. Moreover, because all the residents were in wheelchairs, their relative locations were inferred based on their facial locations. Only the faces of the elderly were detected, particularly as the nursing care staff were wearing medical masks throughout the sessions with Nadine. We adopted the Dlib library with its pre-trained convolutional neural network $(\mathrm{CNN})$ to implement the face detector.

The expression recogniser categorised the expressions of detected faces. We considered eight expressions: Neutral, Happy, Sad, Surprise, Fear, Disgust, Anger, and Contempt. To this end, the ResNet-50 [108] was used, with the

\footnotetext{
$\overline{1 \text { http://dlib.net/ }}$

${ }^{2}$ https://github.com/open-mmlab/mmaction2
} 

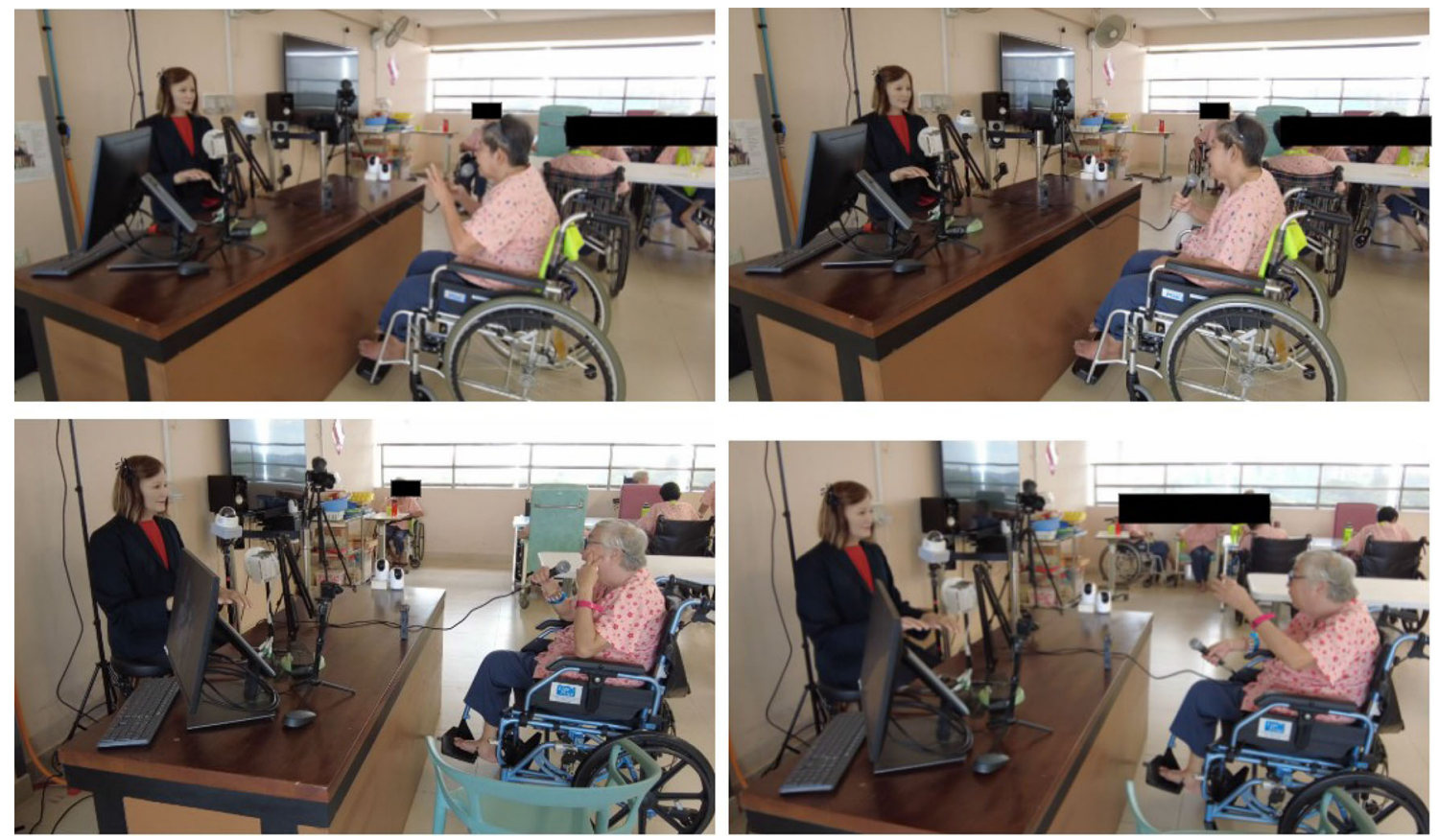

Fig. 5 Residents interacting with Nadine in one-to-one sessions

CNN architecture as the backbone, to categorise expressions. The recogniser was trained on the largest in-thewild facial expressions dataset AffectNet [109] with about 320K (excluding None, Uncertain and Non-Face categories) images till the network was converged. In order to disentangle emotions during sessions, the expressions were grouped into 3 categories: Positive, Negative, and Neutral. The positive category consisted of Happy and Surprise, the negative of Sad, Fear, Disgust, Anger, and Contempt, and the neutral solely of the neutral expressions of the elderly.

The action detector measured the motions and actions of detected faces, generating action proposals, which are the locations and confidences of detecting an action. We implemented the action detector based on the pre-trained temporal segment network [110] provided in the MMAction2 library. The action detector informed us of the movement of the elderly during the session, as the face detector detected only their faces.

The optical flow estimator monitored moving targets. We estimated dense optical flow via the recurrent all-pairs field transformation network. For an arbitrary region in each frame during movement, the average magnitude of the estimated optical flow in the region was used to measure the intensity of movement of the elderly during the sessions.

The above DNNs were useful in spontaneous facial expression recognition, Activity and Movement detection in the continuous video stream of every resident. The quantita- tive measures of Emotional engagement and Movement were as follows:

Positive Emotional Engagement of residents was defined by the following equation using their positive expressions in every frame, where $s_{t}$ and $s u r_{t}$ are the confidences of detecting Smile and Surprise expressions, respectively:

smile $=\frac{1}{L} \sum_{l=1}^{L} \frac{1}{n_{l}} \sum_{t=1}^{n_{l}} s_{t}$

surprise $=\frac{1}{L} \sum_{l=1}^{L} \frac{1}{n_{l}} \sum_{t=1}^{n_{l}} s u r_{t}$

Negative Emotional Engagement of residents was defined by the following equation using their negative expressions in every frame, where $\operatorname{sad}_{t}, f_{t}$, disg $_{t}$, ang $_{t}$ and con $_{t}$ are the confidences of detecting Sadness, Fear, Disgust, Anger, and Contempt, respectively:

sadness $=\frac{1}{L} \sum_{l=1}^{L} \frac{1}{n_{l}} \sum_{t=1}^{n_{l}} s a d_{t}$

fear $=\frac{1}{L} \sum_{l=1}^{L} \frac{1}{n_{l}} \sum_{t=1}^{n_{l}} f_{t}$

disgust $=\frac{1}{L} \sum_{l=1}^{L} \frac{1}{n_{l}} \sum_{t=1}^{n_{l}} \operatorname{disg}_{t}$ 


$$
\begin{aligned}
& \text { anger }=\frac{1}{L} \sum_{l=1}^{L} \frac{1}{n_{l}} \sum_{t=1}^{n_{l}} \operatorname{ang}_{t} \\
& \text { contempt }=\frac{1}{L} \sum_{l=1}^{L} \frac{1}{n_{l}} \sum_{t=1}^{n_{l}} \operatorname{con}_{t}
\end{aligned}
$$

For Activity and the Movement, we used the activity detection and the optical flow estimator, where $o_{t}$ and $d_{t}$ are the average magnitude of optical flow and the confidence of detecting activity, respectively, as follows:

$$
\begin{aligned}
& \text { activity }=\frac{1}{L} \sum_{l=1}^{L} \frac{1}{n_{l}} \sum_{t=1}^{n_{l}} o_{t} \\
& \text { body_movement }=\frac{1}{L} \sum_{l=1}^{L} \frac{1}{n_{l}} \sum_{t=1}^{n_{l}} d_{t}
\end{aligned}
$$

\subsubsection{Video data analysis using observational tool}

Residents were observed during their interactions with Nadine using video recording with the following tools:

- Observed Emotion Rating Scale (OERS) to determine the emotions expressed by the residents and

- Menorah Park Engagement Scale (MPES) to determine the level of engagement of residents.

The OERS and MPES observation data were collected over 4 sessions, with each session lasting from 8-25 mins. A summary of the 10 case studies was compiled to capture the changes and progress of residents. This summary was used to validate the results and findings of the observational data and qualitatively evaluate residents' progress using a 3-domain conceptual framework [111].

The 3-domain conceptual framework (3D Framework) was developed to evaluate the impact of the one-to-one interaction with Nadine. This holistic framework that includes the psychosocial, emotional, and cognitive domains aimed to explain the impact of the one-to-one resident-Nadine interaction through the various domains and dimensions. The framework is conceptually organised in the following manner:

- Psychosocial Domain: This domain includes emotions, personality, self-esteem, and relationships that impacted empathy-related behaviours that residents demonstrated during interaction with Nadine.

\section{- Empathy-related Behaviours}

- Emotional Domain: This includes the feelings and emotions that residents demonstrated during interaction with Nadine.
- Emotional Expression

- Cognitive Domain: This includes the mental processes, thinking, learning, and understanding that residents demonstrated during interaction with Nadine.

- Communication and Language Abilities

- Orientation, Attention, and Memory

\section{Results}

\subsection{Computer vision method}

In order to understand the emotional reactions of the residents when interacting with Nadine, a repeated-measure ANOVA was conducted, revealing significant differences in the emotions experienced by the residents $(F(1,316)=$ $1818.306, p>.001)$. The levels of various emotions can be seen in Fig. 7

Emotional patterns between the first ten and the last ten sessions were not different, as indicated by the absence of an interaction effect in the mixed ANOVA $(F(7,1442)=$ $.834, p=.559)$ and also observable in Fig. 8.

In order to determine how Nadine's presence affected the need for the activities of the care staff, the frequency of their visits was used as a predictor in linear regression, with the optical flow as the criterion. The model was significant $(F(1,333)=7.959, p=.005, \beta=.153)$, indicating that the activity of the care staff increased with Nadine's presence over time. To determine the impact of Nadine's presence on residents' activity, linear regression with the frequency of their visits as the predictor and the body score as the criterion was performed. There were no significant connections between the two $(F(1,335)=.589, p=.443)$. The mean number of visits was 14.25, with a standard deviation of 5.28. The frequency of visits for each of the residents can be seen in Table 2.

The relationship between the number of visits and various emotions is presented in Table 3. People who interacted with the robot more showed more neutral expressions, less fear, and smiled less. The other correlations were not significant at the $\alpha=.05$ level.

The average duration of the conversations was $909 \mathrm{sec}-$ onds (15 minutes and 9 seconds), with the standard correlation of 0.515 . The serial number of the session successfully predicted the conversation length $(F(1,335)=18.610, p<$ $.001, \beta=.229$ ) which increased over time. . Conversation length correlated negatively with smile and positively with neutral at the $\alpha=.05$ level (Table 4).

The data from the observation of video material of the two-week open session indicate that participants mostly felt positive emotions when interacting with Nadine; their predominant emotions were neutral and happiness (as shown in 

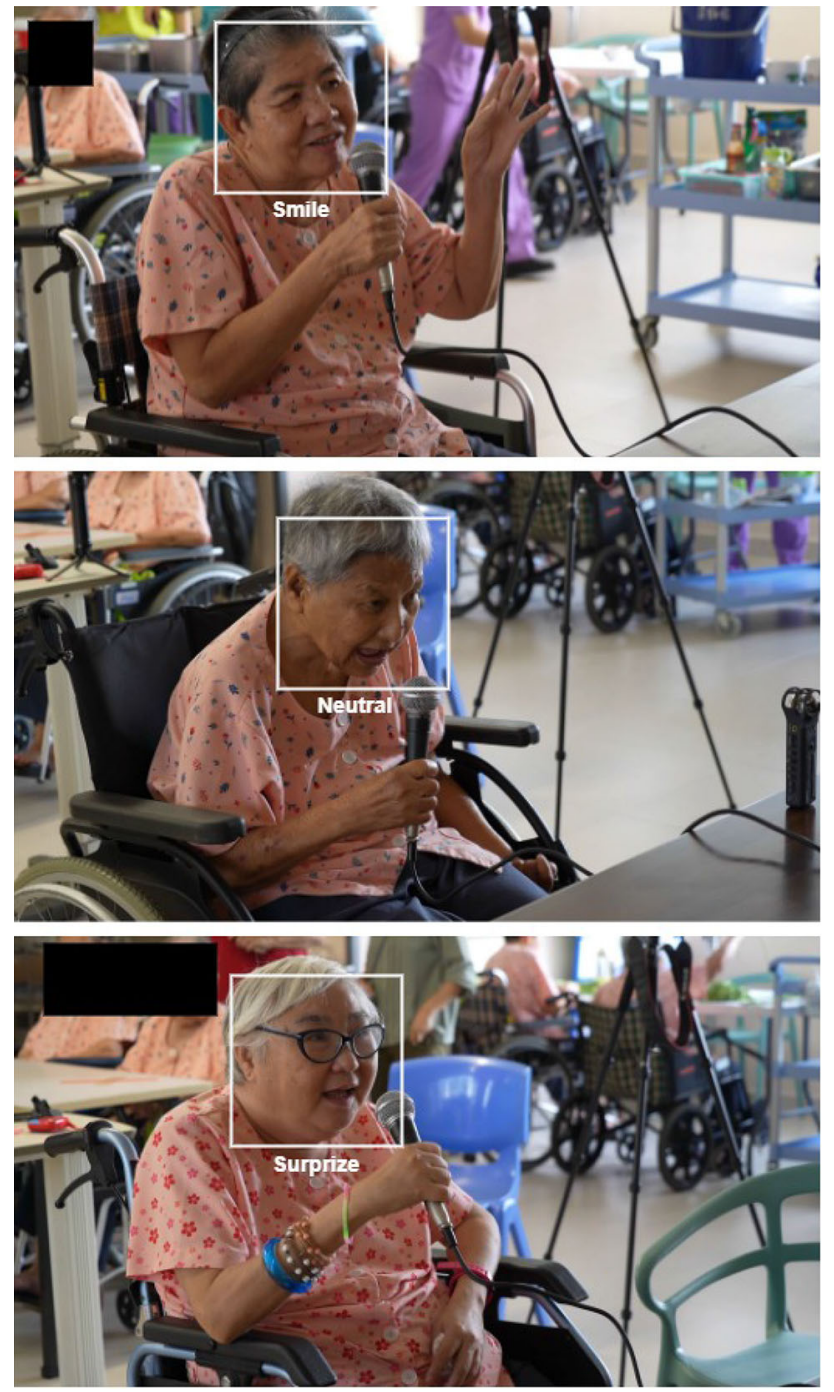

Fig. 6 Different emotions recognised during one-to-one sessions

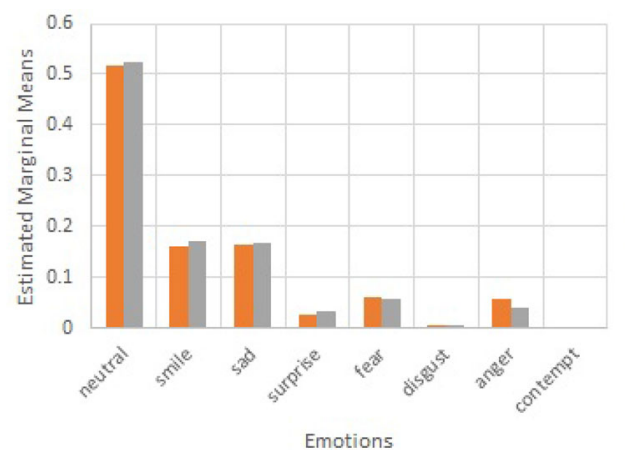

Fig. 7 Means of different emotional expression

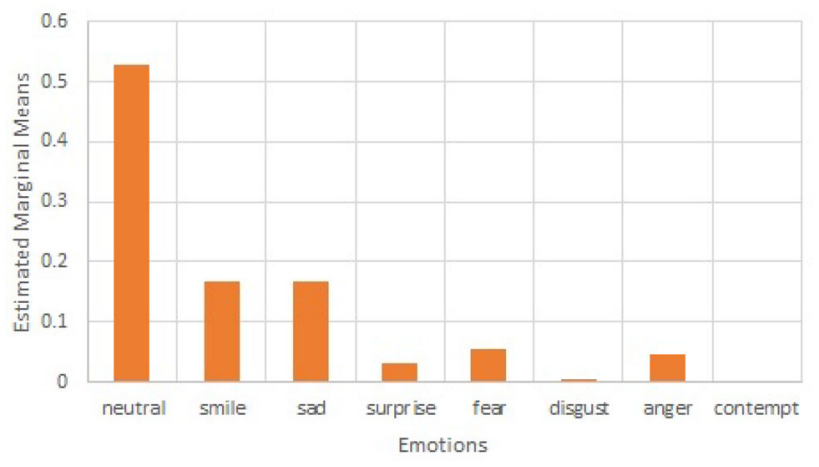

Fig. 8 Comparing emotional patterns between the first and the last 10 sessions

Table 2 Frequency of visits for each resident

\begin{tabular}{lrl}
\hline Participant & Frequency & Body Score \\
\hline 1 & 20 & 0.17850973219 \\
2 & 10 & 0.18772688969 \\
3 & 20 & 0.19229858410 \\
4 & 10 & 0.19545845097 \\
5 & 12 & 0.20085960005 \\
6 & 5 & 0.21649030833 \\
7 & 22 & 0.20298815893 \\
8 & 20 & 0.19874696114 \\
9 & 11 & 0.22216335714 \\
10 & 8 & 0.19246970280 \\
11 & 11 & 0.20890980764 \\
12 & 10 & 0.21042497391 \\
13 & 8 & 0.20599271300 \\
14 & 9 & 0.19257581925 \\
\hline
\end{tabular}

Table 3 The correlations between various emotions and the frequency of visiting the robot

\begin{tabular}{lll}
\hline Emotions & Pearson Correlation & Sig. (2-tailed) \\
\hline Neutral & .132 & 0.015 \\
Smile & -.117 & 0.032 \\
Sad & 0.003 & 0.957 \\
Surprise & -0.004 & 0.939 \\
Fear & -.402 & 0.000 \\
Disgust & 0.069 & 0.208 \\
Anger & 0.074 & 0.175 \\
Contempt & 0.073 & 0.180 \\
Body Score & -0.093 & 0.088 \\
Optical Flow & 0.104 & 0.058 \\
\hline
\end{tabular}


Table 4 The correlations between various emotions and the length of conversation

\begin{tabular}{lll}
\hline Emotion & Pearson Correlation & Sig. (2-tailed) \\
\hline Neutral & 0.067 & 0.218 \\
Smile & .116 & 0.033 \\
Sad & -.112 & 0.040 \\
Surprise & -0.041 & 0.455 \\
Fear & -0.027 & 0.628 \\
Disgust & 0.018 & 0.742 \\
Anger & -0.049 & 0.371 \\
Contempt & -0.005 & 0.931 \\
Body Score & -0.035 & 0.519 \\
Optical Flow & 0.036 & 0.508 \\
\hline
\end{tabular}

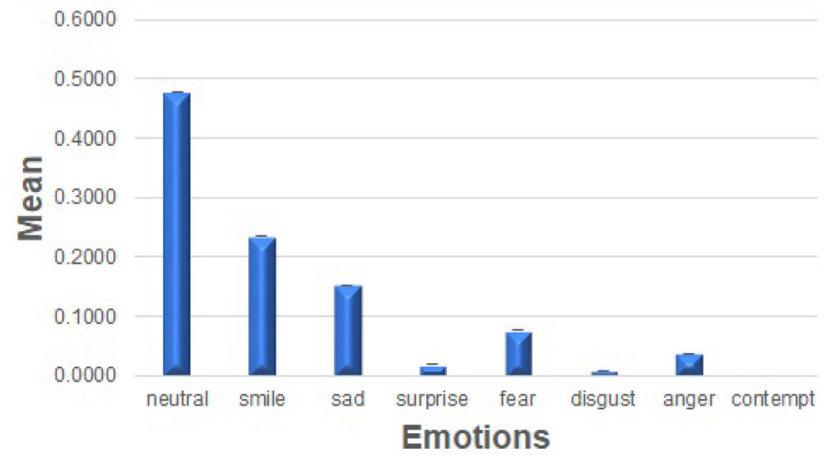

Fig. 9 Emotion expression during open sessions

Fig. 9). Furthermore, participants never or very rarely showed disgust, contempt, fear, anger, and surprise; they showed a moderate amount of sadness. Pearson's correlations revealed no difference in emotions based on the amount of time the residents spent with Nadine ( $r$ values ranging from .011 to $.205, p$ values ranging from .174 to .943 ).

\subsection{Observational Tools}

OERS and MPES observational data showed positive changes in residents' emotional state and engagement level over the 29 sessions of 1-to-1 interactions with Nadine.

Using the MPES tool, we observed residents' engagement levels at baseline. The first 10 sessions yielded 10\% Other Engagement (OE1), 30\% Passive Engagement (PE1) and $60 \%$ Constructive Engagement (CE1). The engagement levels then steadily improved, as seen in the shift towards CE in the subsequent 9 sessions (100\% CEu2) and final $10(90 \%$ CE2 and 10\% CE1). The MPES tool also showed improvements in residents' engagement time, from less than half of the session at baseline to more than half of the session towards the end of the program, as shown in Fig. 10. In general, residents demonstrated improvement in the quality and

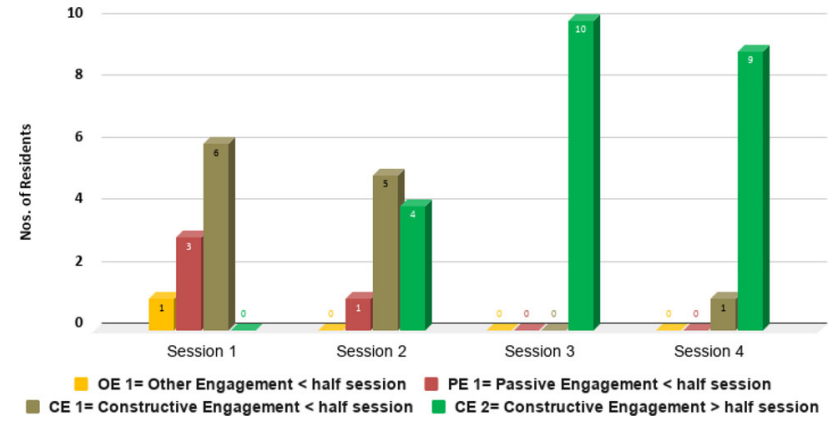

Fig. 10 MPES Summary. Session one denotes the initial 10 sessions; Session two shows the subsequent 4 sessions; Session three indicates the next 5 sessions; Session four represents the final 10 sessions

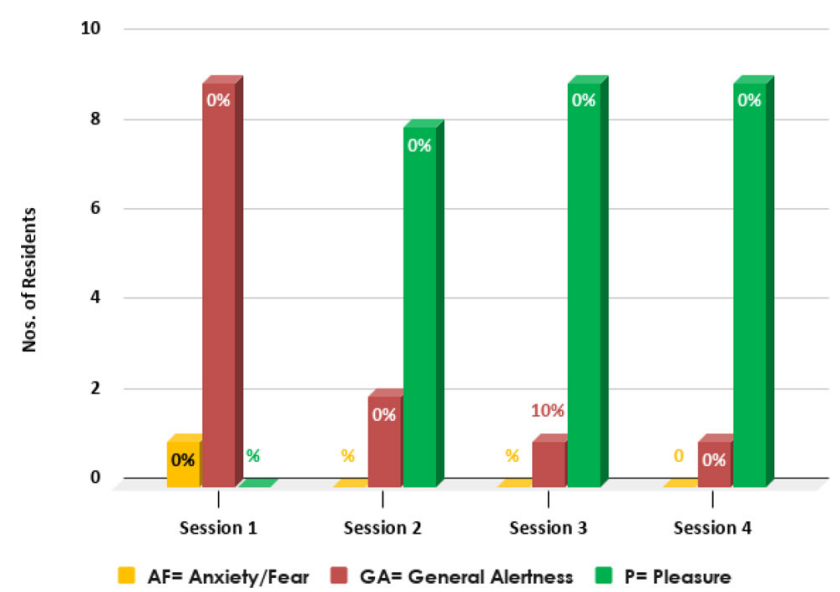

Fig. 11 OERS Summary. Session one denotes the initial 10 sessions; Session two shows the subsequent 4 sessions; Session three indicates the next 5 sessions; Session four represents the final 10 sessions

duration of their engagement over the interaction programme with Nadine.

Per the OERS tool, as seen in Fig. 11, the emotion ratings of the 10 baseline sessions were $10 \% \mathrm{AF}$ and $90 \% \mathrm{GA}$, which progressively improved over the interaction programme as the residents' emotions improved to $90 \% \mathrm{P}, 10 \% \mathrm{GA}$, and $0 \%$ of $\mathrm{AF}$.

\section{Conclusion and discussion}

We placed Nadine at a nursing home and studied the effects of her presence in one-to-one interactions with the residents through different means. A psychotherapist performed the studies via two chosen methods: computer- and observationbased assessments.

Contrary to expectations and previous findings [112], Nadine's presence was associated with more activity from the staff over time. A few factors can explain this increase in the activity of the care staff during resident-Nadine interactions. First, residents started to engage more with Nadine 
over period of time. For residents to initiate conversations with Nadine or continue the conversations they needed help from the staff in picking up the mic and holding it. Also, Nadine's English and Mandarin modules were unfamiliar to the residents, requiring staff to frequently translate and explain Nadine "expressions" and language. Residents who only spoke the dialect depended on the staff for translation to "talk" to Nadine. However, when Nadine gave appropriate responses, residents were observed to respond proactively too. The residents interacted with Nadine, on average, half of each day, indicating a moderate interest in interacting with Nadine.

The residents interacted with Nadine on average a half of the days that she was there. This indicates moderate interest of theirs for interacting with her, which is to be expected from the residents of a home for the elderly. However, those who interacted with her more showed much less fear, indicating that they felt more relaxed when interacting with her. They also smiled slightly less, but this may be attributed to them just normally interacting with Nadine. This is also confirmed by the fact that they expressed neutral emotions more, which is in line with previous studies which showed more calmness after interacting with Paro [29] but also contradictory to studies which showed less neutral affect for residents interacting with Paro [30].

On average the residents conversed with Nadine for around 15 minutes. This is most likely the attention span that they are able to invest in the conversation with her. It may also be the limit of their interest in the interaction. With time, the residents became more and more accustomed to Nadine, as the conversations became longer over time. Furthermore, the residents showed less smiling and more neutral expressions with longer conversations. This is probably due to them finding Nadine less funny or mesmerizing over time, but more interesting as a conversation partner.

The findings indicate significant positive changes noted in the residents' responses (well-being) across the interaction programme with Nadine. The key findings from the observational results suggest that residents responded positively to Nadine through increased positive emotional expression, quality of engagement, and engagement duration. These outcomes were partially supported by the numerical data from the computer- and observation-based methods, which showed no changes in positive emotions that were rather high throughout the assessment. Furthermore, disgust decreased with time. Additionally, residents' positive emotions (like smile and neutral) overwhelmingly dominated negative ones (like fear, disgust, contempt, and anger); sadness was moderately expressed but still at a lesser degree than smile and neutral emotions.

Analytical findings using both the observational data and case studies were encouraging for human-robot interaction (HRI), suggesting the following:
- Improved well-being for residents in nursing homes: Residents in nursing homes appeared to accept and benefit from their interactions with Nadine, impacting their psychosocial, emotional, and cognitive needs. All our participants demonstrated responses that surpassed the usual nursing home activity engagement; they had opportunities to display the different domains of empathy that provided a sense of purpose and connection with the social robot. The residents also showed higher activity based on numerically increased optical flow, which is excellent for their motoric and social development. This type of engagement is often not encountered in nursing homes; it provides opportunities for residents to challenges their curiosity and try to understand the social robot, motivates them to find ways to connect with it, and instils in them the patience and nurturing spirit towards helping their companion. Eventually, there were noticeable improvements in the communication abilities for $90 \%$ of the residents, regardless of their cognitive abilities. Nadine instilled in the residents a sense of purpose and affection, allowing them to care for and nurture the robot.

- The residents who interacted less frequently with Nadine were probably afraid of her: Fear and the frequency of interactions with Nadine correlated negatively, indicating that the elderly who interacted less with her may have feared her. Despite her highly humanoid appearance and behaviour, some of the elderly still feared her, which is unfortunate and a missed opportunity for development. The elderly probably need more time and education to get used to Nadine and stop being afraid. However, the apparent positivity others derived from interacting with Nadine could have spread among the fearful residents over time.

- Emotional expression Responses: Those who interacted more with Nadine showed much less fear and an increasing level of affection for Nadine through their nonverbal and verbal communications, indicating that they felt more relaxed with her. These residents also smiled slightly less, possibly because they perceived their interaction with Nadine as purely normal. Their more frequent expression of neutral emotions supports this assumption, which is in line with observations from previous studies showing more calmness after interacting with Paro [29] However, our observation contradicts the view from another study with less neutral affect for residents interacting with Paro [30]. Still, our inclusion of new tests (presented above) that previous studies had not run should tilt the pendulum of advantage towards our findings.

- Positive intervention for residents with cognitive impairment or dementia: Residents with cognitive impairment and dementia appeared to improve their cognitive abilities as they interacted with Nadine. As seen in the 
eight residents with cognitive impairment and/or dementia, their communication and language abilities and mental processes improved significantly. Despite their cognitive impairment, their level of empathy appeared reasonably intact and may have compensated for their cognitive deficits and promoted appropriate responses and behaviours; this sparks exciting possible interventions where social robots could stimulate and promote the unaffected senses in persons with cognitive impairment.

- Increased productivity by augmenting or reducing human resources: Social robots can augment or reduce the staffing needed in nursing homes. This study featured the use of a social robot that was operational at fixed timing. Residents only interacted with Nadine at specific times. Despite the robot's rigidity and inconsistent performance, the residents were very accommodating and affectionate and nurtured it.

Since Nadine has a humanoid appearance and the ability to communicate, read, and make facial expressions related to emotions, it is logical to assume that her presence can simultaneously improve the state of residents in nursing homes and reduce the burden on the nursing home staff. The realism of Nadine's appearance and interactions is of paramount importance for her usage in human interactions, especially amongst the elderly. Because this group of citizens is least familiar with technology, this gap could be bridged using human-like robots. All the benefits of having people do a particular job could henceforth be combined with the benefits of using robots, which leads to the best possible outcomes for both users and organisations. That is why research on humanoid robots is so important and why it needs further development.

This study showed that using Nadine in a one-to-one interaction (video captured during all sessions ${ }^{3}$ ) setting could be beneficial to cognitively impaired residents in nursing homes, which is a step in the right direction. Future studies should continue investigating these issues and determining all the settings in which humanoid robots' usage could be beneficial.

\section{Future research}

We confirmed that using social robots can undoubtedly help the well-being of care home residents. However, much scientific work must still be conducted on and with these robots to ensure the continuity of users' well-being daily: more research has to be conducted on speech recognition and

\footnotetext{
${ }^{3}$ https://www.dropbox.com/sh/hln4fhnj15o8d95/ AACWKdFDI9r5HDjuCQSIVXpRa?dl=0
}

understanding, the awareness of social robots, multi-party interaction, and the capability to move around and intervene with residents. The social robot should also combine multi-functions to grasp objects and bring them wherever the resident is.

A better speech recogniser must also be developed to understand the broken/soft speech spoken by the elderly. We observed that Nadine could not always answer the elderly correctly due to her inability to understand their speech, an issue not faced by healthy adults. In general, speech recognition systems are optimised to an average adult's voice, with speech tending to exhibit a lower accuracy rate when recognising an older adult's voice because of speech articulation and speaking style. The elderly's speech patterns have a slower speech rate with lengthier inter-syllabic silence and slightly lower speech intelligibility. Therefore, the speech synthesiser must be modified to adapt speech output to make it easier for the elderly to understand them. Speech understanding significantly degrades with ageing, particularly in noisy environments. A robot should speak slower and have a higher volume with a low tone to help the elderly understand and interact effectively. The synthesiser must convey appropriate emotions while maintaining the speed of the robot speech. Age-related deficits in speech-in-noise understanding pose a significant problem for older adults. There is a need to develop a better and dedicated speech synthesiser for assistive robots that serve the purpose of companionship to the elderly.

Our experiments demonstrate the need for socially assistive robots to operate in environments with multiple users. The robot control systems that govern these multi-party interactions must be evaluated from technical and social standpoints(97). Social robots are becoming unstuck in more and more situations where they must interact with multiple users simultaneously. We believe that the multi-party interaction system will render robots more communicative, cooperative, intuitive, capable of meeting expectations, and, overall, able to make a better impression.

Our findings provide an excellent opportunity to develop a mobile social robot that increases accessibility and interaction opportunities. A roving social robot with humanoid features could support the existing staffing resources as it can generate optimal psychosocial, emotional, and cognitive responses without the constant presence of a human worker. At study sites, a roving robot could serve as an enhancement to the workforce by moving around to generate active and passive engagement from the residents within the daily activity area through conversations with and among the residents, providing video and audio reminiscence materials, and being an exciting and interesting object to behold.

Acknowledgements This research is partly supported by the National Research Foundation, Singapore, under its International Research Cen- 
tres in Singapore Funding Initiative, and Institute for Media Innovation, Nanyang Technological University (IMI-NTU). Any opinions, findings, and conclusions or recommendations expressed in this material are those of the author(s) and do not reflect the views of National Research Foundation, Singapore. We are very thankful to the institutional review board (IRB) for their guidelines and support in ethical issues. Special thanks to Chai Kooi Foong, Linda Lim, and Sau Wai from Bright Hill Evergreen Home for their continuous support during this research. We would like to thank our colleagues Tham Yiep Soon for his strong technical support during the study and Ashwini Lawate for her help in pre-processing the video material.

Open Access This article is licensed under a Creative Commons Attribution 4.0 International License, which permits use, sharing, adaptation, distribution and reproduction in any medium or format, as long as you give appropriate credit to the original author(s) and the source, provide a link to the Creative Commons licence, and indicate if changes were made. The images or other third party material in this article are included in the article's Creative Commons licence, unless indicated otherwise in a credit line to the material. If material is not included in the article's Creative Commons licence and your intended use is not permitted by statutory regulation or exceeds the permitted use, you will need to obtain permission directly from the copyright holder. To view a copy of this licence, visit http://creativecomm ons.org/licenses/by/4.0/.

\section{References}

1. Panou, M., Bekiaris, E., Touliou, K., Cabrera, M.: "Use cases for optimising services promoting autonomous mobility of elderly with cognitive impairments," (2015)

2. Panou, M., Cabrera, M., Bekiaris, E., Touliou, K.: "Ict services for prolonging independent living ofelderly with cognitive impairments." AAATE, (2015)

3. Agrigoroaie, R., Ferland, F., Tapus, A.: "The enrichme project: Lessons learnt from a first interaction with the elderly," In: International Conference on Social Robotics. Springer, pp. 735-745 (2016)

4. Tobis, S., Cylkowska-Nowak, M., Wieczorowska-Tobis, K., Pawlaczyk, M., Suwalska, A.: Occupational therapy students' perceptions of the role of robots in the care for older people living in the community. Occupational therapy international 2017, (2017)

5. Ramanathan, M., Mishra, N., Magnenat Thalmann, N.: "Nadine humanoid social robotics platform," In: Computer Graphics International Conference. Springer, pp. 490-496 (2019)

6. Van Haitsma, K., Klapper, J.: Observed emotion rating scale. J. Mental Health Aging 5(1), 69-81 (1999)

7. Judge, K.S., Camp, C.J., Orsulic-Jeras, S.: Use of montessoribased activities for clients with dementia in adult day care: effects on engagement. Am. J. Alzheimer's Disease 15(1), 42-46 (2000)

8. Pollack, M.E., Brown, L., Colbry, D., Orosz, C., Peintner, B., Ramakrishnan, S., Engberg, S., Matthews, J.T., Dunbar-Jacob, J., McCarthy, C.E., et al.: Pearl: A mobile robotic assistant for the elderly. AAAI Workshop Automation Eldercare 2002, 85-91 (2002)

9. Pineau, J., Montemerlo, M., Pollack, M., Roy, N., Thrun, S.: Towards robotic assistants in nursing homes: challenges and results. Robot. Auton. Syst. 42(3-4), 271-281 (2003)

10. Law, M., Sutherland, C., Ahn, H.S., MacDonald, B.A., Peri, K., Johanson, D.L., Vajsakovic, D.-S., Kerse, N., Broadbent, E.: Developing assistive robots for people with mild cognitive impairment and mild dementia: a qualitative study with older adults and experts in aged care. BMJ Open 9(9), e031937 (2019)
11. Kim, G.H., Jeon, S., Im, K., Kwon, H., Lee, B., Kim, G., Jeong, H., Han, N., Seo, S., Cho, H., Noh, Y., Park, S.E., Kim, H., Hwang, J., Yoon, C., Ye, B.S., Chin, J., Kim, J.-H., Na, D.: Structural brain changes after traditional and robot-assisted multi-domain cognitive training in community-dwelling healthy elderly. PLOS ONE 10, e0123251 (2015)

12. Fischinger, D., Einramhof, P., Papoutsakis, K., Wohlkinger, W., Mayer, P., Panek, P., Hofmann, S., Koertner, T., Weiss, A., Argyros, A., et al.: Hobbit, a care robot supporting independent living at home: first prototype and lessons learned. Robot. Auton. Syst. 75, 60-78 (2016)

13. Vincze, M., Fischinger, D., Bajones, M., Wolf, D., Suchi, M., Lammer, L., Weiss, A., Pripfl, J., Körtner, T., Gisinger, C.: "What older adults would like a robot to do in their homes-first results from a user study in the homes of users," In: Proceedings of ISR 2016: 47st International Symposium on Robotics. VDE, pp. 1-7 (2016)

14. Bajones, M., Fischinger, D., Weiss, A., Puente, P.D.L., Wolf, D., Vincze, M., Körtner, T., Weninger, M., Papoutsakis, K., Michel, D., et al.: Results of field trials with a mobile service robot for older adults in 16 private households. ACM Trans. Human-Robot Interaction (THRI) 9(2), 1-27 (2019)

15. Mišeikis, J., Caroni, P., Duchamp, P., Gasser, A., Marko, R., Mišeikienè, N., Zwilling, F., de Castelbajac, C., Eicher, L., Früh, M., et al.: Lio-a personal robot assistant for human-robot interaction and care applications. IEEE Robot. Autom. Letts. 5(4), 5339-5346 (2020)

16. Coşar, S., Fernandez-Carmona, M., Agrigoroaie, R., Pages, J., Ferland, F., Zhao, F., Yue, S., Bellotto, N., Tapus, A.: Enrichme: perception and interaction of an assistive robot for the elderly at home. Int. J. Soc. Robot. 12(3), 779-805 (2020)

17. "Ramcip robotic assistant for mci patients at home," In: https:// ramcip-project.eu/

18. Khosla, R., Chu, M.-T.: Embodying care in matilda: an affective communication robot for emotional wellbeing of older people in Australian residential care facilities. ACM Trans. Manag. Inf. Syst.(TMIS) 4(4), 1-33 (2013)

19. Martinez-Martin, E., Escalona, F., Cazorla, M.: Socially assistive robots for older adults and people with autism: an overview. Electronics 9(2), 367 (2020)

20. Salatino, C., Pigini, L., Van Kol, M.M.E., Gower, V., Andrich, R., Munaro, G., Rosso, R., Castellani, A.P., Farina, E.: A robotic solution for assisting people with mci at home: preliminary tests of the enrichme system. Studies Health Technol. Inf. 242, 484-491 (2017)

21. Klamer, T., Allouch, S.B., Heylen, D.: "adventures of harveyuse, acceptance of and relationship building with a social robot in a domestic environment," In: International Conference on HumanRobot Personal Relationship. Springer, pp. 74-82 (2010)

22. Pu, L., Moyle, W., Jones, C., Todorovic, M.: The effectiveness of social robots for older adults: a systematic review and metaanalysis of randomized controlled studies. Gerontol. 59(1), e37e51 (2019)

23. Tsujimura, M., Ide, H., Yu, W., Kodate, N., Ishimaru, M., Shimamura, A., Suwa, S.: "The essential needs for home-care robots in Japan," J. Enabling Technol., (2020)

24. Alves-Oliveira, P., Petisca, S., Correia, F., Maia, N., Paiva, A.: "Social robots for older adults: framework of activities for aging in place with robots," In: International Conference on Social Robotics. Springer, pp. 11-20 (2015)

25. Cohen-Mansfield, J., Dakheel-Ali, M., Marx, M.S.: Engagement in persons with dementia: the concept and its measurement. Am. J. Geriatr. psychiatry 17(4), 299-307 (2009)

26. Bradwell, H.L., Edwards, K.J., Winnington, R., Thill, S., Jones, R.B.: Companion robots for older people: importance of usercentred design demonstrated through observations and focus 
groups comparing preferences of older people and roboticists in South West England. BMJ Open 9(9), e032468 (2019)

27. Lohse, M., Hegel, F., Wrede, B.: "Domestic applications for social robots: an online survey on the influence of appearance and capabilities," (2008)

28. Wada, K., Shibata, T.: Living with seal robots-its sociopsychological and physiological influences on the elderly at a care house. IEEE Trans. Robot. 23(5), 972-980 (2007)

29. Lane, G.W., Noronha, D., Rivera, A., Craig, K., Yee, C., Mills, B., Villanueva, E.: Effectiveness of a social robot, paro, in a va long-term care setting. Psychol. Services 13(3), 292 (2016)

30. Moyle, W., Jones, C.J., Murfield, J.E., Thalib, L., Beattie, E.R., Shum, D.K., O'Dwyer, S.T., Mervin, M.C., Draper, B.M.: Use of a robotic seal as a therapeutic tool to improve dementia symptoms: a cluster-randomized controlled trial. J. Am. Med. Dir. Assoc. 18(9), 766-773 (2017)

31. Robinson, H., MacDonald, B., Kerse, N., Broadbent, E.: The psychosocial effects of a companion robot: a randomized controlled trial. J. Am. Med. Dir. Assoc. 14(9), 661-667 (2013)

32. Tapus, A.: "Improving the quality of life of people with dementia through the use of socially assistive robots," In: 2009 Advanced Technologies for Enhanced Quality of Life. IEEE, pp. 81-86 (2009)

33. Tapus, A., Tapus, C., Matarić, M.J.: "Music therapist robot for individuals with cognitive impairments," In: Proceedings of the 4th ACM/IEEE international conference on Human robot interaction, pp. 297-298 (2009)

34. Tapus, A., Tapus, C., Mataric, M.J.: "The use of socially assistive robots in the design of intelligent cognitive therapies for people with dementia," In: 2009 IEEE international conference on rehabilitation robotics. IEEE, pp. 924-929 (2009)

35. Tapus, A., Tapus, C., Mataric, M.: "Music therapist robot: a solution for helping people with cognitive impairments," In: IJCAI Workshop on Intelligent Systems for Assisted Cognition, July, Pasadena, CA, (2009)

36. Tamura, T., Yonemitsu, S., Itoh, A., Oikawa, D., Kawakami, A., Higashi, Y., Fujimooto, T., Nakajima, K.: Is an entertainment robot useful in the care of elderly people with severe dementia? J. Gerontol. Series A: Biol. Sci. Med. Sci. 59(1), M83-M85 (2004)

37. Banks, M.R., Willoughby, L.M., Banks, W.A.: Animal-assisted therapy and loneliness in nursing homes: use of robotic versus living dogs. J. Am. Med. Dir. Assoc. 9(3), 173-177 (2008)

38. Ananto, R.A., Young, J.E.: "Robot pets for everyone: the untapped potential for domestic social robots," (2020)

39. Hamada, T., Okubo, H., Inoue, K., Maruyama, J., Onari, H., Kagawa, Y., Hashimoto, T.: "Robot therapy as for recreation for elderly people with dementia-game recreation using a pet-type robot," In: RO-MAN 2008-The 17th IEEE International Symposium on Robot and Human Interactive Communication. IEEE, pp. 174-179 (2008)

40. Sakairi, K.: "Research of robot-assisted activity for the elderly with senile dementia in a group home," In: SICE 2004 Annual Conference, vol. 3. IEEE, pp. 2092-2094 (2004)

41. Homes, S., Nugent, B.C., Augusto, J.: Human-robot user studies in eldercare: lessons learned. Smart Homes Beyond: Icost 2006, 4 (2006)

42. Barata, A., Martins, H., Mendes, R.: Application of social robots for symptom control in institutionalized elderly patients with dementia. Int. J. Robot. Eng. 2, 002 (2015)

43. Libin, A., Cohen-Mansfield, J.: Therapeutic robocat for nursing home residents with dementia: preliminary inquiry. Am. J. Alzheimer's Disease Other Dementias ® 19(2), 111-116 (2004)

44. Moyle, W., Jones, C., Sung, B., Bramble, M., O’Dwyer, S., Blumenstein, M., Estivill-Castro, V.: What effect does an animal robot called cuddler have on the engagement and emotional response of older people with dementia? a pilot feasibility study. Int. J. Soc. Robot. 8(1), 145-156 (2016)

45. Pripfl, J., Körtner, T., Batko-Klein, D., Hebesberger, D., Weninger, M., Gisinger, C., Frennert, S., Eftring, H., Antona, M., Adami, I., et al.: "Results of a real world trial with a mobile social service robot for older adults," In: 2016 11th ACM/IEEE International Conference on Human-Robot Interaction (HRI). IEEE, pp. $497-$ 498 (2016)

46. Wada, K., Shibata, T.: "Robot therapy in a care house-its sociopsychological and physiological effects on the residents," In: Proceedings 2006 IEEE International Conference on Robotics and Automation, 2006. ICRA 2006. IEEE, pp. 3966-3971 (2006)

47. Turkle, S., Taggart, W., Kidd, C.D., Dasté, O.: Relational artifacts with children and elders: the complexities of cybercompanionship. Connect. Sci. 18(4), 347-361 (2006)

48. Giusti, L., Marti, P.: "Interpretative dynamics in human robot interaction," In: ROMAN 2006-The 15th IEEE International Symposium on Robot and Human Interactive Communication. IEEE, pp. 111-116 (2006)

49. Wada, K., Shibata, T.: "Robot therapy in a care house - results of case studies-," In: ROMAN 2006-The 15th IEEE International Symposium on Robot and Human Interactive Communication, pp. 581-586 (2006)

50. Chang, W., Šabanovic, S., Huber, L.: "Use of seal-like robot paro in sensory group therapy for older adults with dementia," In: 2013 8th ACM/IEEE International Conference on Human-Robot Interaction (HRI), pp. 101-102 (2013)

51. Šabanović, S., Chang, W.-L.: Socializing robots: constructing robotic sociality in the design and use of the assistive robot paro. AI Soc. 31(4), 537-551 (2016)

52. Šabanović, S., Bennett, C.C., Chang, W.-L., Huber, L.: "Paro robot affects diverse interaction modalities in group sensory therapy for older adults with dementia," In: 2013 IEEE 13th international conference on rehabilitation robotics (ICORR). IEEE, pp. 1-6 (2013)

53. Broekens, J., Heerink, M., Rosendal, H., et al.: Assistive social robots in elderly care: a review. Gerontechnology 8(2), 94-103 (2009)

54. Fernaeus, Y., Håkansson, M., Jacobsson, M., Ljungblad, S.: "How do you play with a robotic toy animal? a long-term study of pleo," In: Proceedings of the 9th international Conference on interaction Design and Children, pp. 39-48 (2010)

55. Fischer, K.: How people talk with robots: designing dialog to reduce user uncertainty. AI Mag. 32(4), 31-38 (2011)

56. Guiot, D., Kerekes, M., Sengès, E.: "Living with buddy: can a social robot help elderly with loss of autonomy to age well?" In: 28th IEEE RO-MAN Internet Of Intelligent Robotic Things For Healthy Living and Active Ageing, International Conference on Robot \& Human Interactive Communication, pp. 23-26 (2019)

57. Shen, Z., Wu, Y.: "Investigation of practical use of humanoid robots in elderly care centres," In: Proceedings of the Fourth International Conference on Human Agent Interaction, pp. 63 66 (2016)

58. Céspedes, N., Múnera, M., Gómez, C., Cifuentes, C.A.: Social human-robot interaction for gait rehabilitation. IEEE Trans. Neural Syst. Rehabili.Eng. 28(6), 1299-1307 (2020)

59. Carros, F., Meurer, J., Löffler, D., Unbehaun, D., Matthies, S., Koch, I., Wieching, R., Randall, D., Hassenzahl, M., Wulf, V.: "Exploring human-robot interaction with the elderly: Results from a ten-week case study in a care home," In: Proceedings of the 2020 CHI Conference on Human Factors in Computing Systems, ser. CHI '20. New York, NY, USA: Association for Computing Machinery, pp. 1-12 (2020)

60. Ke, C., Lou, V.W.-Q., Tan, K.C.-K., Wai, M.Y., Chan, L.L.: Changes in technology acceptance among older people with 
dementia: the role of social robot engagement. Int. J. Med. Inf. 141, 104241 (2020)

61. Melkas, H., Hennala, L., Pekkarinen, S., Kyrki, V.: Impacts of robot implementation on care personnel and clients in elderlycare institutions. Int. J. Med. Inf. 134, 104041 (2020)

62. Huisman, C., Kort, H.: "Two-year use of care robot zora in dutch nursing homes: An evaluation study," In: Healthcare, vol. 7, no. 1. Multidisciplinary Digital Publishing Institute, p. 31. (2019)

63. Cruz-Sandoval, D., Morales-Tellez, A., Sandoval, E.B., Favela, J.: "A social robot as therapy facilitator in interventions to deal with dementia-related behavioral symptoms," In: Proceedings of the $2020 \mathrm{ACM}$ /IEEE International Conference on Human-Robot Interaction, pp. 161-169 (2020)

64. Moharana, S., Panduro, A.E., Lee, H.R., Riek, L.D.: "Robots for joy, robots for sorrow: community based robot design for dementia caregivers," In: 2019 14th ACM/IEEE International Conference on Human-Robot Interaction (HRI). IEEE, pp. 458-467 (2019)

65. Abdollahi, H., Mollahosseini, A., Lane, J.T., Mahoor, M.H.: "A pilot study on using an intelligent life-like robot as a companion for elderly individuals with dementia and depression," In: 2017 IEEE-RAS 17th International Conference on Humanoid Robotics (Humanoids). IEEE, pp. 541-546 (2017)

66. Chu, M.-T., Khosla, R., Khaksar, S.M.S., Nguyen, K.: Service innovation through social robot engagement to improve dementia care quality. Assist. Technol. 29(1), 8-18 (2017)

67. Rouaix, N., Retru-Chavastel, L., Rigaud, A.-S., Monnet, C., Lenoir, H., Pino, M.: Affective and engagement issues in the conception and assessment of a robot-assisted psychomotor therapy for persons with dementia. Front. Psychol. 8, 950 (2017)

68. Shibata, T.: Therapeutic seal robot as biofeedback medical device: qualitative and quantitative evaluations of robot therapy in dementia care. Proc. IEEE 100(8), 2527-2538 (2012)

69. Thunberg, S., Rönnqvist, L., Ziemke, T.: "Do robot pets decrease agitation in dementia patients?" In: International Conference on Social Robotics. Springer, pp. 616-627 (2020)

70. Li, J., Louie, W.G., Mohamed, S., Despond, F., Nejat, G.: "A userstudy with tangy the bingo facilitating robot and long-term care residents," In: 2016 IEEE International Symposium on Robotics and Intelligent Sensors (IRIS), pp. 109-115 (2016)

71. Studies, B.C.: Meet stevie the social robot that holds bingo lessons in a care home. (2020). [Online]. Available: https:// businesscasestudies.co.uk/meet-stevie-the-social-robot-thatholds-bingo-lessons-in-a-care-home/

72. Law, M., Sutherland, C., Ahn, H.S., MacDonald, B.A., Peri, K., Johanson, D.L., Vajsakovic, D.-S., Kerse, N., Broadbent, E.: "Developing assistive robots for people with mild cognitive impairment and mild dementia: a qualitative study with older adults and experts in aged care," BMJ Open, 9(9), (2019). [Online]. Available: https://bmjopen.bmj.com/content/9/ 9/e031937

73. Perugia, G., Rodríguez-Martín, D., Boladeras, M., Català, A., Barakova, E., Rauterberg, M.: Quantity of movement as a measure of engagement for dementia: The influence of motivational disorders. Am. J. Alzheimer s Disease Other Dementias 33, 11 (2017)

74. Passler Bates, D., Young, J.E.: "Snugglebot: A novel cuddly companion robot design," In: Proceedings of the 8th International Conference on Human-Agent Interaction, pp. 260-262 (2020)

75. Fasola, J., Mataric, M.J.: "Robot exercise instructor: a socially assistive robot system to monitor and encourage physical exercise for the elderly," In: 19th International Symposium in Robot and Human Interactive Communication. IEEE, pp. 416-421 (2010)

76. Nishio, T., Yoshikawa, Y., Sakai, K., Iio, T., Chiba, M., Asami, T., Isoda, Y., Ishiguro, H.: The effects of physically embodied multiple conversation robots on the elderly. Front. Robot. AI 8, $61(2021)$
77. Henschel, A., Hortensius, R., Cross, E.S.: "Social cognition in the age of human-robot interaction," Trends in Neurosciences, 43(6), 373-384, (2020). [Online]. Available: http://www. sciencedirect.com/science/article/pii/S0166223620300734

78. Obayashi, K., Kodate, N., Masuyama, S.: Measuring the impact of age, gender and dementia on communication-robot interventions in residential care homes. Geriatr. Gerontol. Int. 20(4), 373-378 (2020)

79. Chen, K., Lou, V.W.-Q., Tan, K.C.-K., Wai, M.-Y., Chan, L.-L.: Effects of a humanoid companion robot on dementia symptoms and caregiver distress for residents in long-term care. J. Am. Med. Dir. Assoc. 21(11), 1724-1728 (2020)

80. Sabelli, A.M., Kanda, T., Hagita, N.: "A conversational robot in an elderly care center: an ethnographic study," In: 2011 6th ACM/IEEE international conference on human-robot interaction (HRI). IEEE, pp. 37-44 (2011)

81. Karunarathne, D., Morales, Y., Nomura, T., Kanda, T., Ishiguro, H.: Will older adults accept a humanoid robot as a walking partner? Int. J. Soc. Robot. 11(2), 343-358 (2019)

82. Ferland, F., Tapus, A.: "System integration for the enrichme project: A service robot for care facilities for the elderly," In: RO-MAN Workshop on Behavior Adaptation, Interaction and Learning for Assistive Robotics, (2016)

83. Robosoft. [Online]. Available: www.robosoft.com

84. Cylkowska-Nowak, M., Tobis, S., Salatino, C., Tapus, A., Suwalska, A.: "The robots in elderly care," In: 2nd International Multidisciplinary Scientific Conference on Social Sciences and Arts SGEM2015, (2015)

85. Sato, M., Yasuhara, Y., Osaka, K., Ito, H., Dino, M.J.S., Ong, I.L., Zhao, Y., Tanioka, T.: Rehabilitation care with pepper humanoid robot: a qualitative case study of older patients with schizophrenia and/or dementia in Japan. Enfermería Clínica 30, 32-36 (2020)

86. Feingold Polak, R., Tzedek, S.L.: "Social robot for rehabilitation: Expert clinicians and post-stroke patients' evaluation following a long-term intervention,” In: Proceedings of the 2020 ACM/IEEE International Conference on Human-Robot Interaction, pp. 151$160(2020)$

87. Tuisku, O., Pekkarinen, S., Hennala, L., Melkas, H.: Robots do not replace a nurse with a beating heart. Information Technology \& People (2019)

88. Pigini, L., Facal, D., Blasi, L., Andrich, R.: Service robots in elderly care at home: users' needs and perceptions as a basis for concept development. Technol. Disabil. 24(4), 303-311 (2012)

89. Bradwell, H.L., Winnington, R., Thill, S., Jones, R.B.: Ethical perceptions towards real-world use of companion robots with older people and people with dementia: survey opinions among younger adults. BMC Geriatrics 20(1), 1-10 (2020)

90. Schüssler, S., Zuschnegg, J., Paletta, L., Fellner, M., Lodron, G., Steiner, J., Pansy-Resch, S., Lammer, L., Prodromou, D., Brunsch, S., et al.: The effects of a humanoid socially assistive robot versus tablet training on psychosocial and physical outcomes of persons with dementia: protocol for a mixed methods study. JMIR Res. Protoc. 9(2), e14927 (2020)

91. Baka, E., Vishwanath, A., Mishra, N., Vleioras, G., Magnenat Thalmann, N.: "Am I talking to a human or a robot?: A preliminary study of human's perception in human-humanoid interaction and its effects in cognitive and emotional states," In: Computer Graphics International Conference. Springer, pp. 240-252 (2019)

92. Rudzicz, F., Wang, R., Begum, M., Mihailidis, A.: "Speech recognition in alzheimer's disease with personal assistive robots," In: Proceedings of the 5th Workshop on Speech and Language Processing for Assistive Technologies, pp. 20-28 (2014)

93. De Carolis, B., Ferilli, S., Palestra, G.: Simulating empathic behavior in a social assistive robot. Multimed. Tools Appl. 76(4), 5073-5094 (2017) 
94. Sánchez, M.-L., Correa, M., Martínez, L., Ruiz-del Solar, J.: “An episodic long-term memory for robots: the bender case," In: Robot Soccer World Cup. Springer, pp. 264-275 (2015)

95. Simoens, P., Dragone, M., Saffiotti, A.: The internet of robotic things: a review of concept, added value and applications. Int. J. Adv. Robot. Syst. 15(1), 1729881418759424 (2018)

96. Xiao, Y., Zhang, Z., Beck, A., Yuan, J., Thalmann, D.: Humanrobot interaction by understanding upper body gestures. Presence: teleoperators and virtual environments 23(2), 133-154 (2014)

97. Beck, A., Zhijun, Z., Magnenat Thalmann, N.: "Motion control for social behaviors," In: Context Aware Human-Robot and HumanAgent Interaction. Springer, pp. 237-256 (2016)

98. Magnenat Thalmann, N., Zhang, Z.: "Social robots and virtual humans as assistive tools for improving our quality of life," In: 2014 5th International Conference on Digital Home. IEEE, pp. 1-7 (2014)

99. Mishra, N., Ramanathan, M., Satapathy, R., Cambria, E., Magnenat Thalmann, N.: "Can a humanoid robot be part of the organizational workforce? a user study leveraging sentiment analysis," In: 2019 28th IEEE International Conference on Robot and Human Interactive Communication (RO-MAN). IEEE, pp. 1-7 (2019)

100. Eyal, N.: Hooked: How to Build Habit-Forming Products. Penguin, London (2014)

101. Neven, L.: but obviously not for me: robots, laboratories and the defiant identity of elder test users. Sociol. Health Illn. 32(2), 335347 (2010)

102. Lee, H.R., Tan, H., Šabanović, S.: "That robot is not for me: Addressing stereotypes of aging in assistive robot design," In: 2016 25th IEEE International Symposium on Robot and Human Interactive Communication (RO-MAN). IEEE, pp. 312317 (2016)

103. Chang, W.-L., Šabanović, S.: "Exploring taiwanese nursing homes as product ecologies for assistive robots," In: 2014 IEEE International Workshop on Advanced Robotics and its Social Impacts. IEEE, pp. 32-37 (2014)

104. Kc, U., Chodorowski, J.: A case study of adding proactivity in indoor social robots using belief-desire-intention (bdi) model. Biomimetics 4(4), 74 (2019)

105. Zhang, X., Sugano, Y., Fritz, M., Bulling, A.: "It's written all over your face: Full-face appearance-based gaze estimation," In: Proceedings of the IEEE Conference on Computer Vision and Pattern Recognition Workshops, pp. 51-60 (2017)

106. Amos, B., Ludwiczuk, B., Satyanarayanan, M., et al.: Openface: A general-purpose face recognition library with mobile applications. CMU School of Computer Science 6(2), (2016)

107. Teed, Z., Deng, J.: "Raft: Recurrent all-pairs field transforms for optical flow," In: Proceedings of the IEEE Conference on Computer Vision and Pattern Recognition, (2020)

108. He, K., Zhang, X., Ren, S., Sun, J.: "Deep residual learning for image recognition," In: Proceedings of European Conference on Computer Vision, pp. 770-778 (2016)

109. Mollahosseini, A., Hasani, B., Mahoor, M.H.: Affectnet: a database for facial expression, valence, and arousal computing in the wild. IEEE Trans. Affect. Comput. 10(1), 18-31 (2017)

110. Wang, L., Xiong, Y., Wang, Z., Qiao, Y., Lin, D., Tang, X., Van Gool, L.: Temporal segment networks for action recognition in videos. IEEE Trans. Pattern Anal. Mach. Intell. 41(11), 27402755 (2018)

111. Tisseron, S., Tordo, F., Baddoura, R.: Testing empathy with robots: a model in four dimensions and sixteen ítems. Int. J. Soc. Robot. 7(1), 97-102 (2015)

112. Thodberg, K., Sørensen, L.U., Videbech, P.B., Poulsen, P.H., Houbak, B., Damgaard, V., Keseler, I., Edwards, D., Christensen, J.W.: Behavioral responses of nursing home residents to visits from a person with a dog, a robot seal or a toy cat. Anthrozoös 29(1), 107-121 (2016)

Publisher's Note Springer Nature remains neutral with regard to jurisdictional claims in published maps and institutional affiliations.

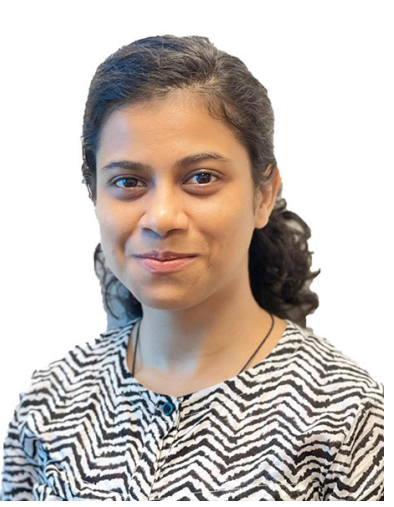

Gauri Tulsulkar is currently a researcher at the Institute for Media Innovation at Nanyang Technological University, Singapore. She obtained her Bachelor's degree from Manipal Institute of technology, India. She has 5 years of extensive research experience. Her interests are computer vision, human-robot interaction and data analysis.

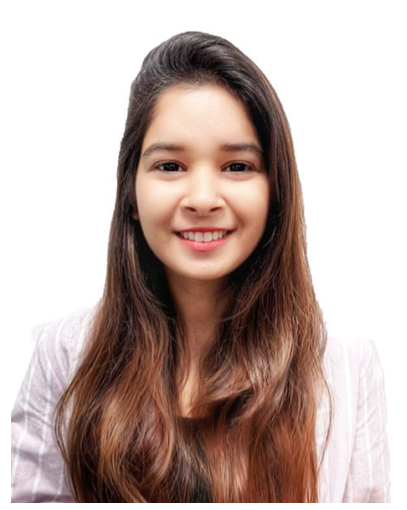

Nidhi Mishra has a Bachelor in Technology from Indian Institute of Information Technology, Allahabad. She has gained five years of research experience in humancomputer interaction, humanrobot interaction, and natural language processing. Her research interest spans various subdomains of natural language programming (NLP), artificial intelligence (AI) and machine learning (ML).

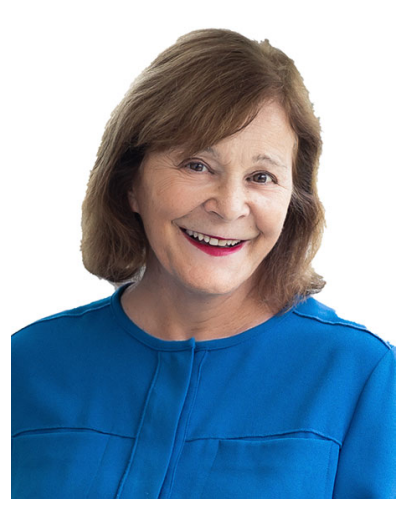

Nadia Magnenat Thalmann has pioneered the field of Virtual Humans at a very early stage at the University of Montreal in Canada before moving to the University of Geneva in 1989 where she founded the interdisciplinary research group MIRALab. She has published several landmark papers on the modelling of 3D faces and bodies as well as pioneered the field of physical modelling of clothes. She has also worked intensively on the simulation of the digital patient. Recently in NTU Singapore, she advanced the field of social robotics with her humanoid robot Nadine, similar to herself, that can show emotions, speak naturally and remember facts and emotions. She has received many awards and several honorary doctorates. She is a life member of the Swiss Academy of Engineering Sciences. Nadia Magnenat Thalmann-Wikipedia 


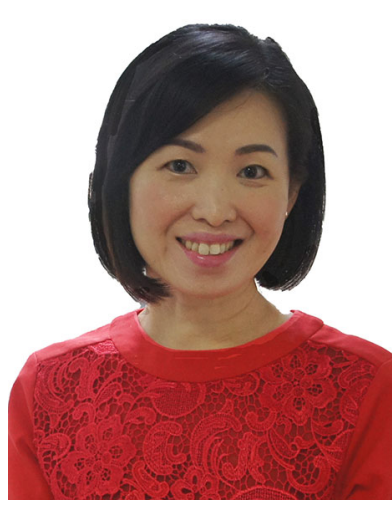

Hwee Er Lim is passionate to transform care for the older persons through innovative and future-ready solutions to promote dignity of care. Hwee Er, with her expertise as a Gerontology Occupational Therapist, strategic leader and founder of Goshen Consultancy Services Pte Ltd, combines innovative clinical and business knowledge to design and implement sustainable personcentred care practices in care for the older persons. She holds a Masters of Health Service Management from University of Sydney, Australia and Bachelor of Health Sciences (Hons), University of Teesside, UK.

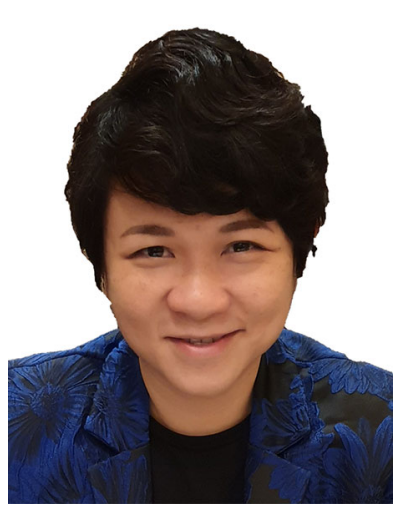

Mei Ping Lee leverages her expertise in organisational development, human resource management and business acumen to influence transformational service delivery in social service organisations. As co-founder of Goshen Consultancy, Mei Ping has led and implemented numerous sector-wide productivity and technology-based projects to promote sustainable and quality person-centred social service delivery. Lee Mei Ping holds a Masters of Business Administration from University of South Australia, Australis and Bachelor of Business, Marketing from Monash University, Australia.

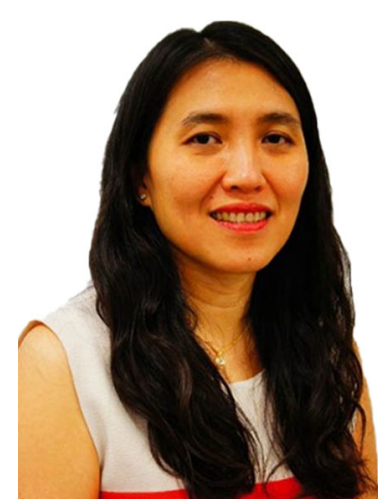

Siok Khoong Cheng is the Chief Executive Officer of Bright Hill Evergreen Home and has been serving the residents of this voluntary welfare home that provides quality health care and shelter for the disadvantaged and aged sick for close to 7 years. Prior to joining the charity sector, Ms Cheng held various senior regional roles with leading global FMCG and logistic companies for more than 25 years 